\title{
Degradation of Styrenic Plastics During Recycling: Impact of Reprocessing Photodegraded Material on Aspect and Mechanical Properties
}

\author{
Charles Signoret ${ }^{1} \cdot$ Marie Edo $^{1} \cdot$ Dominique Lafon $^{3} \cdot$ Anne-Sophie Caro-Bretelle $^{2} \cdot$ José-Marie Lopez-Cuesta $^{1}$. \\ Patrick lenny ${ }^{2}$. Didier Perrin ${ }^{1}$
}

\begin{abstract}
The major technical limitations in polymer recycling are their incompatibility between each other and their ageing. In this study, impact reinforced styrenics, namely HIPS and ABS, were evaluated in the scope of their alterations through recycling photooxidized material. In this purpose, plates were photodegraded in both natural and accelerated conditions. FTIR-ATR was used to monitor their ageing. After the desired ageing durations, plates were ground, extruded and injected into ISO1 dumbbell tensile test specimens to simulate recycling of degraded polymers. Strong interactions were observed between photooxidation and polymer processing through photometry measures, associated color changes, tensile and impact properties. It was noticed that unaged materials displayed only moderated alterations through recycling. Because of their close chemistry, HIPS and ABS share several modifications but ABS was less altered and mainly impact properties were affected. HIPS and ABS difference of sensibilities could be rooted in PB phases different morphologies and grafting between the two materials.
\end{abstract}

Keywords Polymer recycling $\cdot$ WEEE $\cdot$ Styrenics $\cdot$ Colorimetry $\cdot$ Mechanical properties $\cdot$ FTIR

\begin{tabular}{ll}
$\begin{array}{ll}\text { Abbreviations } \\
\text { ABS }\end{array}$ & $\begin{array}{l}\text { Acrylonitrile butadiene styrene } \\
\text { Aext }\end{array}$ \\
& $\begin{array}{l}\text { Reextruded samples from accelerated } \\
\text { ageing }\end{array}$ \\
AN & Acrylonitrile \\
ASA & Acrylonitrile styrene acrylic rubber \\
ATR & Attenuated total reflection \\
CRI & Color Rendering Index \\
CRT & Cathodic ray tube \\
FTIR & Fourier transform infrared \\
GPPS & General purpose polystyrene \\
HIPS & High impact polystyrene \\
LED & Light-emitting diodes \\
Next & Reextruded samples from natural ageing \\
NIR-HSI & Near-infrared hyperspectral imagery \\
& \\
\hline $\begin{array}{l}\text { Didier Perrin } \\
\text { didier.perrin @ mines-ales.fr }\end{array}$ \\
Polymers Composites and Hybrids (PCH), IMT Mines Ales, \\
Alès, France \\
LMGC, IMT Mines Ales, Univ Montpellier, CNRS, Alès, \\
France \\
Euromov Montpellier, IMT Mines Ales, CNRS, Alès, France
\end{tabular}

$\begin{array}{ll}\text { PB } & \text { Polybutadiene } \\ \text { PS } & \text { Polystyrene } \\ \text { SAN } & \text { Styrene acrylonitrile } \\ \text { V } & \text { Virgin samples } \\ \text { Vext } & \text { Reextruded unaged samples } \\ \text { UV } & \text { Ultraviolet } \\ \text { WEEE or W3E } & \text { Waste of electrical and electronic } \\ & \text { equipment } \\ \text { WEEP } & \text { WEEE plastics }\end{array}$

\section{Introduction}

Waste of electric and electrical equipment (WEEE) generation is rapidly increasing with the constant worldwide rise of Gross Domestic Products [1], especially in populated developing countries as India or China, tending to meet unsustainable models which, by excessive goods consumption, energy production and waste generation, deplete and pollute the environment more than it can sustain durably for our population density. These lifestyles are largely found in occidental countries [2], which themselves have disposed a great part of their WEEE in aforementioned countries [3, 4]. These objects lifespans are also decreasing, with high 
renewal rates, even if they are still functional $[5,6]$. Reuse, repairing/remanufacturing are advised but not sufficiently applied [7-9]. Also, black color generalized among WEEE plastics (WEEP), especially for professional computers casing or telephones, as shown on Fig. 1. Carbon black limits polymer ageing by absorbing UV-rays, even if this phenomenon can be only delayed and slowed down $[10,11]$. This surface ageing, mainly by photo-oxidation, is often characterized by an infamously yellowing [12] as seen on the 1990s telephone station of Fig. 1. Interestingly enough, plastic retained a white color where the handset and station meet, as it was unexposed to the sun and thus avoided photooxidation. However, polymers tainted in mass with carbon black become invisible to near-infrared hyperspectral imagery (NIR-HSI), the currently most used technology with sink-float for industrial sorting [13, 14], mandatory to obtain satisfactory properties through mechanical recycling $[15,16]$. Development of new technologies to overcome this dark plastics sorting issue is currently subject to tremendous research [17-24] and could enable proper recycling of sorted WEEP. Study of styrenics recyclability, especially after ageing, is thus a hot topic.

Nowadays, the main WEEP are styrenics: namely high impact polystyrene (HIPS) and acrylonitrile-butadiene-styrene (ABS) and their respective blends with PPE (polyphenylene ether) and PC (polycarbonate) [25-27]. HIPS and ABS represent together $55 \mathrm{w} \%$ of WEEP according to Maris et al. [25], and $80 \mathrm{w} \%$ according to Stenvall et al. [28]. HIPS and ABS consist of a rigid thermoplastic matrix, respectively polystyrene (PS or GPPS for General Purpose) and the statistical copolymer styrene-acrylonitrile (SAN), in which were incorporated slightly cross-linked polybutadiene (PB) nodules, which dramatically enhance their impact properties [29]. Nodules are generally coarser within HIPS than in
ABS, with a more complex morphology with matrix inclusions [30]. This is due to the respectively preferred synthesis route for each material [31-34]. HIPS is generally synthesized through bulk copolymerization, where the pre-rubber phase is solubilized in styrene monomer before polymerization. This leads to multimodal size distribution and inclusions of polystyrene domains within nodules. Emulsion grafting, the main synthesis route for ABS, consists of a first step of emulsion polymerization and crosslinking of polybutadiene nodules which are then grafted during the matrix polymerization. This enables narrower and way finer rubber particles distribution. These preferences in synthesis routes are justified as impact improvement is optimal for 1-3 $\mu \mathrm{m}$ PB nodules in HIPS but $0.05-0.50 \mu \mathrm{m}$ in ABS [31]. Also, ABS contains generally more PB than HIPS as PB rates are reported from 5 to $30 \mathrm{w} \%$ for ABS [35] but usually from 6 to $8.5 \mathrm{w} \%$ for HIPS and up to $15 \mathrm{w} \%$ at maximum [36].

Even if PB enables very interesting impact properties, it often forbids transparency, slightly lowers the Young modulus and can initiate degradation. Indeed, several studies showed that because of its reactivity, PB could be easily oxidized with temperature or ultraviolet (UV) rays [37, 38]. ASA (acrylonitrile styrene acrylic) is an alternative solution, often applied for outdoor applications, where PB is substituted by acrylic rubber, less sensitive to ageing due to its lack of double bonds [39]. However, because of its price and lower impact properties, ASA is not widely spread.

Styrenics thermo- and photo-oxidations were thus subject to important research. As soon as 1968, Shimada et Kabuki [37] demonstrated that weathering of ABS mainly occurred by PB photooxidation. Davis et Gordon [40] found that pigmentation could strongly interfere with ageing as wavelengths between 295 and $340 \mathrm{~nm}$ were the more impacting.

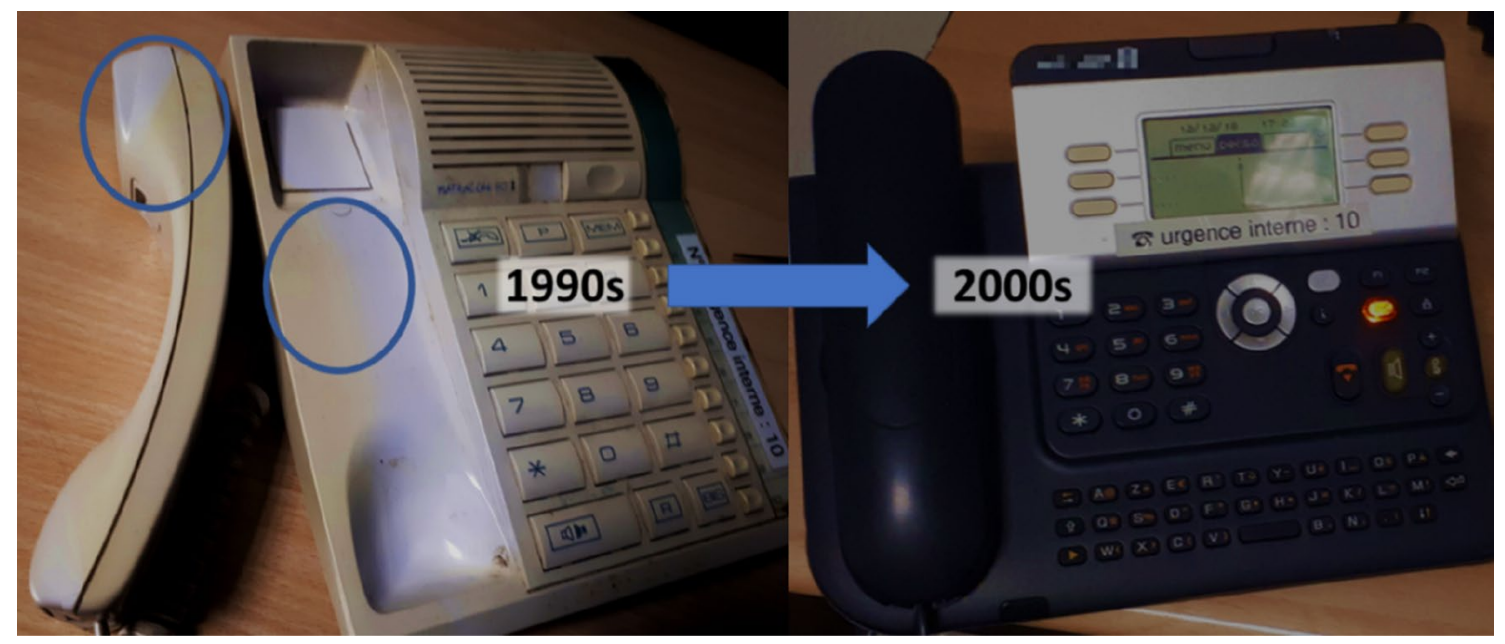

Fig. 1 Example of black coloration generalization for small WEEE plastics-note tint difference between exposed and preserved areas of the 1990s phone station 
Contribution to degradation then strongly decreases with the wavelength. Jouan et Gardette [12, 41] used chemical titration and derivation to differentiate the different oxidized species that occurs during ageing. Notably, they highlighted conjugated species, involving aromatic cycles and newly formed vinyls and carbonyls (Fig. 2), which are a source of discoloration. Thanks to this methodology, Gardette et al. [42] also proposed multiple degradation mechanisms to PS, SAN, HIPS and ABS. They emphasized the initiator role of PB in both HIPS and ABS. Finally, they highlighted that ageing within SAN and PS generates chain scissions and conjugated compounds whereas PB oxidation mainly leads to further crosslinking as illustrated on Fig. 2. Changes in color are thus mainly linked to matrix degradation. Saviello et al. [43] reported and demonstrated that ageing was limited to $70 \mu \mathrm{m}$ deep in ABS, thanks to a "protective" degraded layer, limiting oxygen diffusion limitation and/or absorbing more low wavelengths because of conjugated species [44]. Tiganis et al. [45] found that thermooxidation of ABS was also a surface phenomenon but was sufficient to degrade impact and tensile properties. Wang et al. [46] found strong discoloration and important loss of mechanical properties and flame retardancy of naturally weathered HIPS where photooxidation is the main mechanism. Vilaplana et al. [47] highlighted that thermooxidation could be more detrimental to HIPS than reprocessing (grinding-extrusion) steps. Pérez et al. [48] demonstrated similar results for photooxidation of $\mathrm{ABS}$ and even reported that ABS could be reprocessed up to ten times without important loss of tensile properties.

During plastic recycling, waste materials went through a whole life-cycle, from their first transformation, thermo and/or photo-oxidation during their storage, use and disposal, where they can also suffer from diverse

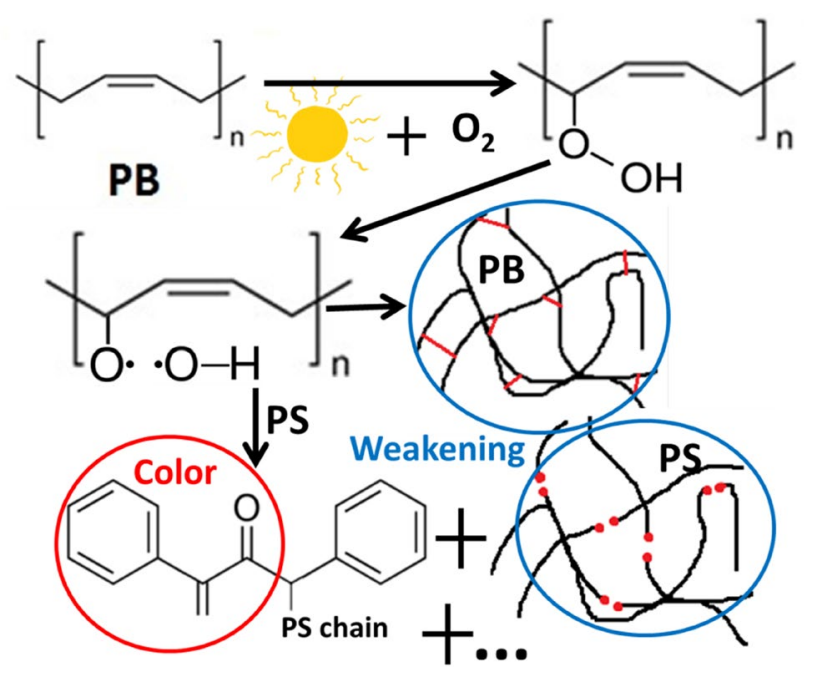

Fig. 2 Summary of phenomena induced by photo-ageing of HIPSpartially applicable to ABS - adapted from literature contaminations. To evaluate possible interactions between photo-ageing and recycling, La Mantia et Gardette [49] reprocessed photo-oxidized LDPE films and found that it permitted partial regeneration of properties that they attributed to homogenization and dilution of defects. Soccalingame et al. [50, 51] studied the reprocessing of naturally and artificially weathered wood flour reinforced PP and also highlighted a similar "regeneration" mechanism and added that shorter chains formed during photodegradation could recrystallize thanks to recycling. Pfaender and his collaborators [52-57] substantially published on the subject of "restabilisation" of polymers, principally polyolefins, PET and PVC, towards their recycling in the goal to maintain interesting properties, through several extrusion steps but also with interaction with photo or thermoageing.

To our knowledge, few studies combined photoageing and reprocessing [49-51, 58, 59], especially on styrenics materials, particularly with colorimetry and impact properties assessment. Boldizar et Möller [60] combined thermal ageing and reprocessing on ABS and found a synergy which strongly impacted melt volume rate and oxidation induction temperature. Stenvall [61] showed that gamma ray irradiations impact conservation of ABS tensile modulus through several reprocessing cycles. Finally, Luzuriaga et al. [59] performed mechanical recycling on LDPE, HDPE, PP and HIPS which went through 6 or 14 days of accelerated ageing, each material displaying different interactions between the two operations. For HIPS, reprocessing permitted recovery of impact strength lost because of ageing, due to a dilution-homogenization mechanism. MFI however was slightly increased during the first 6 days but longer ageing or reprocessing did not change it furtherly. This study aims to evaluate properties changes within HIPS and ABS after the recycling of differently photo-aged materials. A part of articles cited above tend to realize several processing steps on identically aged materials. Here is studied the recycling of materials at different ageing degrees, as collected waste plastics are not uniformly aged. With these elements in mind, one could better plan re-use of weathered waste materials, even if other considerations as formulation, grades differences or polymeric and non-polymeric impurities are also to take into account.

\section{Materials and Methods}

\section{Materials}

Most of styrenics used in this study were provided by Styrolution: Polystyrol 485I for HIPS, Terluran GP35 
for ABS, Luran $388 \mathrm{~S}$ for SAN and Luran S $757 \mathrm{G}$ for ASA. PS crystal 1340 for GPPS was provided by Total Petrochemicals.

\section{Ageing Conditions}

Natural ageing was realized in Alès (France, $44^{\circ} 08^{\prime} 09.0^{\prime \prime} \mathrm{N}$ $4^{\circ} 05^{\prime} 54.3^{\prime \prime} \mathrm{E}$ ) from the beginning of April to the end of July 2018. $100 \times 100 \times 4 \mathrm{~mm}$ plates were attached with coated iron wire on metallic racks shown on Fig. 3 , inclined at $45^{\circ}$ and directly exposed to the south side. Plates were exposed on only one side. FTIR spectra were acquired every week by removing plates less than one hour each time.

Weather conditions were monitored from the 20th of April using a "Hygro Button" device [62] which enables temperature and relative humidity measures directly next to the samples let to age. These values were measured every $30 \mathrm{~min}$. Meteorological data for the months of April and June were also provided by a weather station located in Saint-Christol-lez-Alès, $8 \mathrm{~km}$ to the south. Daily average humidity and daily minimum, maximum and average temperatures are shown on Fig. 4. Whereas minimal values are very coherent, maximal ones are higher with the hygrobouton. Weather station measures were carried out away from light in a ventilated system, according to the World Meteorological Organization. The hygrobouton was directly and severely exposed to sunlight as described above. During ageing, the temperature gap average was of roughly $20^{\circ} \mathrm{C}$ whereas the average temperature rose from about $20^{\circ} \mathrm{C}$ in April up to $30{ }^{\circ} \mathrm{C}$ in July.

Accelerated ageing was performed in a QUV/Spray tester from Q-Lab [63] equipped with UVA-340 lamps, at $65^{\circ} \mathrm{C}$, no humidity conditions and UV-A irradiation at $0.76 \mathrm{~W} /$ $\mathrm{m}^{2}$. Emission spectra of these lamps have reportedly [64] a

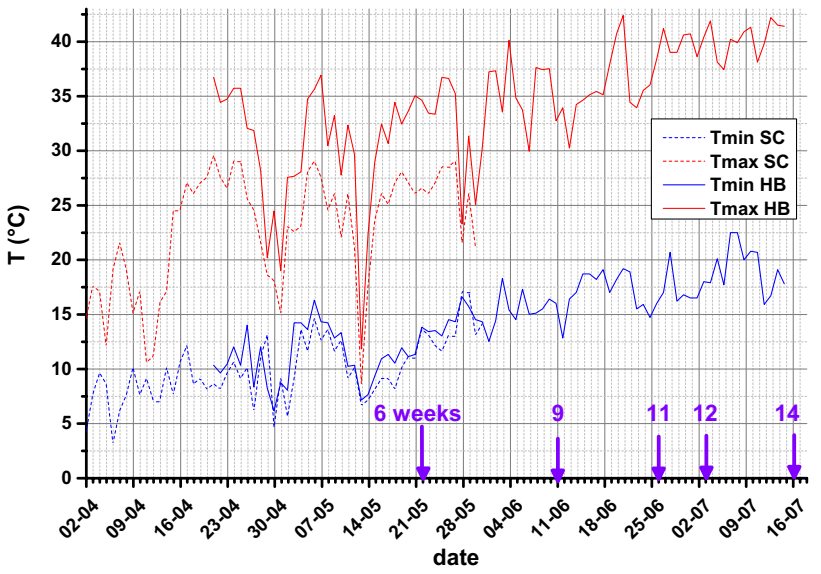

Fig. 4 Temperature monitoring on natural ageing period- "SC" corresponds to Saint-Christol-lez-Alès weather station data, "HB" for hygrobutton-purple arrows correspond to ageing durations for mechanical recycling

Gaussian shape centered on $340 \mathrm{~nm}$, more or less imitating the UV fraction of unfiltered sun light, with low emission at the beginning of visual range, conferring them a light blue hue when in service. Due to the sampler holder geometry $\left(95 \times 63 \mathrm{~mm}^{2}\right)$ seen on Fig. 5, 4-mm thick plates were cut at about $63 \mathrm{~mm}$ wide.

\section{Processing Conditions}

Polymer plates were shredded thanks to a Retsch SM-300 cutting mill with an 8 -mm grid at $800 \mathrm{rpm}$. Polymer pellets or shreds were dried at $80{ }^{\circ} \mathrm{C}$ for at least $16 \mathrm{~h}$ before transformations. Extrusion was realized with a $900 \mathrm{~mm} \mathrm{Clex-}$ tral twin-screw extruder of type $\mathrm{BC} 21$ at $250 \mathrm{rpm}, 220^{\circ} \mathrm{C}$ along the screw, with a $5 \mathrm{~mm}$ nozzle, at a $6 \mathrm{~kg} / \mathrm{h}$ feed speed
Fig. 3 Polymer plates put to natural ageing on metallic racks in Alès, France $\left(44^{\circ} 08^{\prime} 09.0^{\prime \prime} \mathrm{N}\right.$ $\left.4^{\circ} 05^{\prime} 54.3^{\prime \prime} \mathrm{E}\right)$

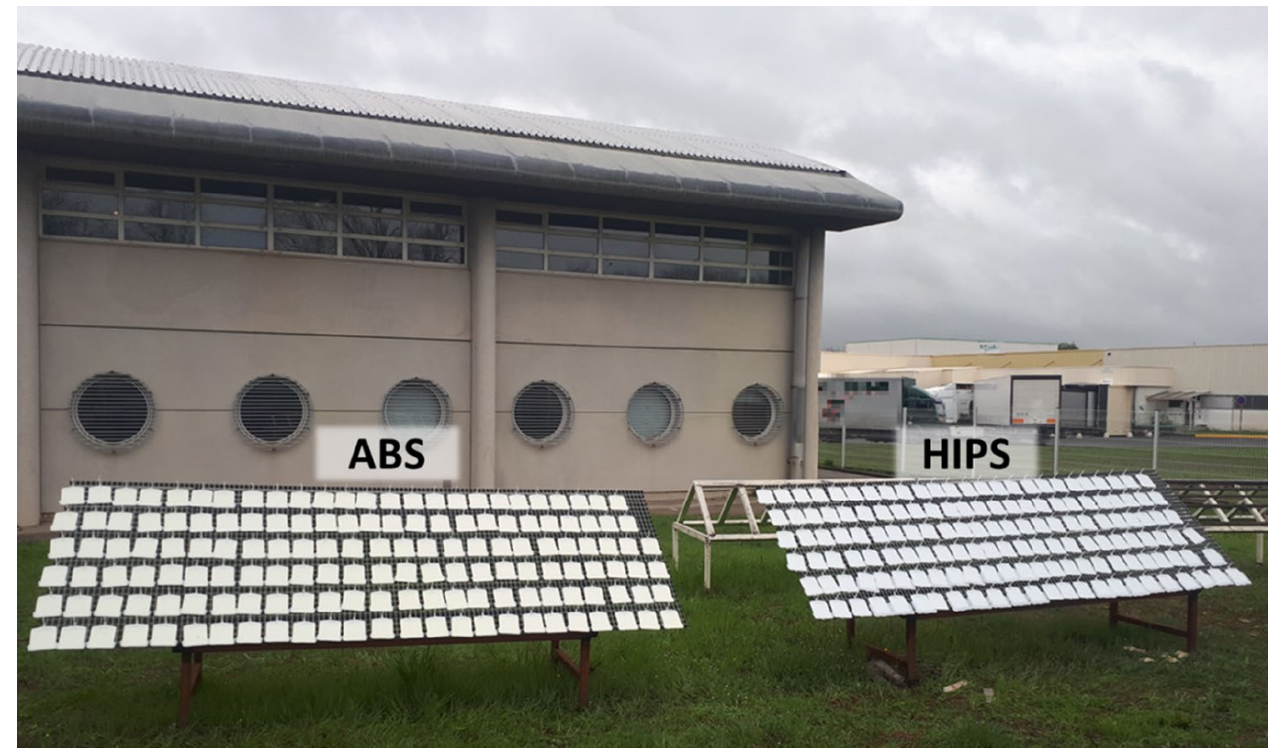


Fig. 5 Q-UV tester for accelerated ageing on cut polymer plates-red circle for UV lamp, green circle for sample holder, aged plate example on bottom right corner (Color figure online)

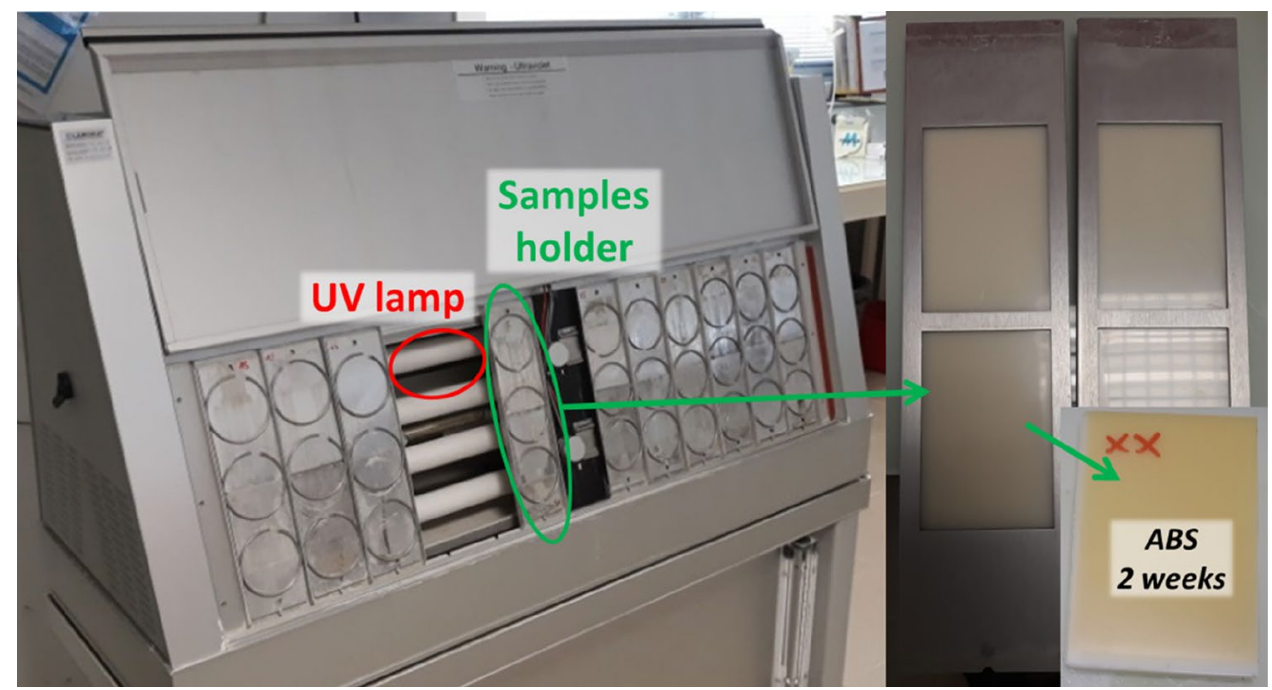

thanks to a K-Tron KQx-2 weighing feeder from Coperion. Extrudate was then pelletized thanks to an SGS-E50 from CF Scheer \& Cie. For mechanical properties, Type A dogbones specimen corresponding to ISO 3167, were injected thanks to a Kraus-Maffei 180/CX 50 molding injection press at $230{ }^{\circ} \mathrm{C}$ which also served for plates injection.

\section{Characterization}

\section{FTIR-ATR Spectroscopy}

A Vertex 70 FT MIR spectrometer from Bruker with an ATR unit was used. The used resolution was of $4 \mathrm{~cm}^{-1}, 16$ scans for background acquisition and 16 scans for the sample spectrum. Spectra were acquired from 4000 to $400 \mathrm{~cm}^{-1}$. All samples were cleaned with ethanol before analysis. Spectra were processed with Matlab2018 and plotted with Origin 9. Spectra were integrally normalized according to the $1452 \mathrm{~cm}^{-1}$ peak corresponding to $\mathrm{CH}_{2}$ stretching.

\section{Photometry}

Photometry measurements were made with a CS 1000 spectroradiometer provided by Konica Minolta. Samples were indirectly illuminated in a dark room with a $4700 \mathrm{~K}$ light source that provides a very good D50 daylight simulation (standard corresponding to horizon light) with a smooth, continuous and full spectral power distribution. Color Rendering Index of the light source is 99.35 . Photo umbrellas were used to create the desired diffuse lighting conditions to avoid specular reflection as samples exhibit flat and shiny surfaces. In order to characterize the incident light, measurements on a white reflectance standard were made before each sample measurement. Reflectances were then calculated on the visible range (380 to $780 \mathrm{~nm}$ ). Colorimetric calculations were performed with the CIE $19312^{\circ}$ standard observer and D65 (noon daylight standard) illuminant [65]. Obtained $(\mathrm{X}, \mathrm{Y}, \mathrm{Z})$ tri stimulus values were then converted into the CIELab system, generating three values: $\mathrm{L}^{*}$ for dark/bright ranges from 0 to $100 ; a^{*}$ and $b^{*}$ evolve on green/red and blue/yellow axis, both being at 0 corresponds to a neutral tint, negative values respectively correspond to green and blue whereas positive ones to red and yellow.

\section{Mechanical Tests}

Tensile tests were performed according to the ISO 527 norm and thanks to a Z010 Zwick press equipped with a $2.5 \mathrm{kN}$ load cell and a Clip-on extensometer. The Young's moduli were measured at a $1 \mathrm{~mm} / \mathrm{min}$ crosshead speed between $0.05 \%$ and $0.25 \%$ of deformation. Further deformations were performed at $10 \mathrm{~mm} / \mathrm{min}\left(1.510^{-3} \mathrm{~s}^{-1}\right)$. Ultimate strains were measured according the crosshead displacement. Instrumented impact tests were done thanks to an impact drop tester Ceast 9340 from Instrom. Both notched and unnotched Charpy impact tests were done at $2.9 \mathrm{~m} / \mathrm{s}$ $\left(3.0 \mathrm{~s}^{-1}\right)$, according to ISO 179 . Results were processed thanks to Matlab 2018b and plotted with Origin 9. Boxplots shown in this work represent median, quarters (horizontal lines), average (cross), minimum and maximum (whiskers).

\section{Ageing-Reprocessing Cycles \& Samples Designation}

Figure 6 illustrates taken routes for samples production. Plates were injected with above mentioned conditions and then subjected to ageing on only one side, about 25 plates by batch, roughly $1 \mathrm{~kg}$. These steps simulate the "first life" of a plastic to recycle. When appropriate durations were met, samples were harvested to be milled. Obtained shreds were extruded and injected into dog-bones specimens with the 


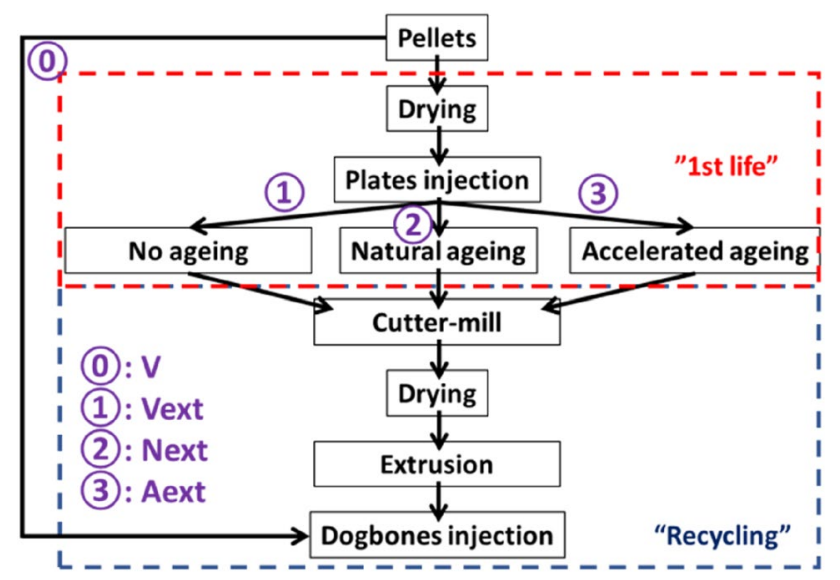

Fig. 6 Samples production routes \& designation

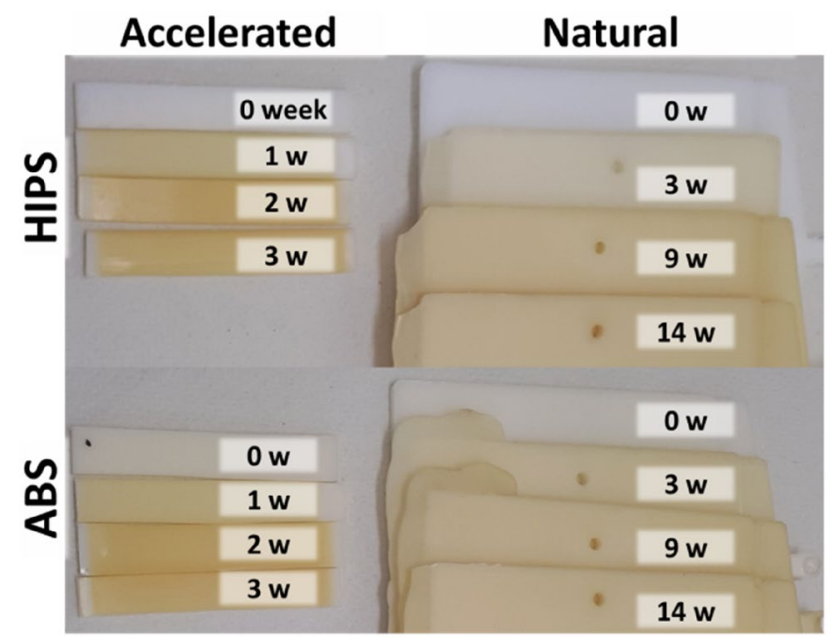

Fig. 7 Pictures of yellowed HIPS \& ABS after natural \& accelerated photo-ageing

conditions mentioned above. This represents the "recycling" step.

At each process cycle, two different control samples were made: the first one being directly injected from pellets ("V" for "virgin") and the other one being unaged plates which went through the same grinding-reextrusion step as the other aged batches ("Vext" for "virgin and extruded"). This aims to differentiate degradations due only to reprocessing and those because of both ageing and reprocessing.

\section{Results and Discussion}

\section{Evolutions During Photodegradation-“1st Life"}

\section{Visual Modifications}

Both accelerated and natural ageing led to more or less important yellowing, well documented in the literature [12, 43, 66, 67]. Different shades can however be observed on Fig. 7, the ones issued from accelerated ageing displaying more vivid colors whereas the ones from natural ageing were duller and darker. As expected, mainly the exposed face went through changes, whereas the unexposed one kept its original aspect, except HIPS for the longer natural ageing exposure. Whereas ABS already had a lightly yellow/brown color from the beginning, it went through moderate changes in comparison with HIPS. Photometry measurements on these samples and recycled ones are presented below, in Part 3.2.1.

\section{Spectroscopic Alterations in Infrared}

FTIR-ATR (Fig. 8) shows growing marks of oxidation in each case. $\mathrm{O}-\mathrm{H}$ stretching corresponds to a large band from 3000 to $3300 \mathrm{~cm}^{-1}$. In the most advanced ageing, a wider band can be observed from 2400 to $3300 \mathrm{~cm}^{-1}$, corresponding to carboxylic acid $\mathrm{O}-\mathrm{H}$ stretching whereas the previous one was associated only to alcohol, in concordance with the literature for styrenics ageing [42]. Difference between these two bands is particularly visible in ABS aged in Q-UV, lefthand bottom corner of Fig. 8. A large band, roughly from 850 to $1350 \mathrm{~cm}^{-1}$ is associated to $\mathrm{C}-\mathrm{O}$ stretching, ethers for the lower wavenumbers around $1025 \mathrm{~cm}^{-1}$, and esters for the highest ones around $1175 \mathrm{~cm}^{-1}$ [42]. For respective maximal durations, it can be noted that accelerated ageing generates relatively more esters than natural ageing. Accordingly, the alcohol specific $\mathrm{OH}$ band is relatively more marked for natural aged samples. This is probably linked to the more advanced ageing state obtained in accelerated ageing at these durations. Also, temperature and irradiance intensities differences could differently influence the many simultaneous reaction rates. In particular, the formation of hydroxyl corresponds to an end to the many potential reactions resulting from the decomposition of hydroperoxides [42]. Also, baseline is more and more deformed as ageing progresses, especially in natural conditions. This shape is characteristic of ATR insofar as the absorption of the low wave numbers is favored because the penetration of the rays is related to its incident energy. This hints for progressive degradation of samples surfaces. When splitting chains and producing volatile compounds [42], roughness can be generated. However, no change was observed with naked eye or to the touch. 
Accelerated

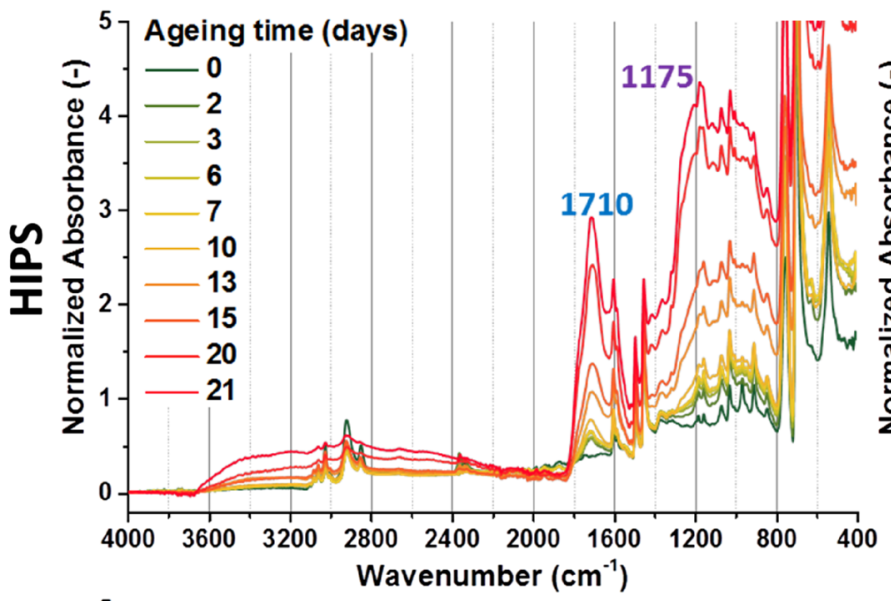

Natural

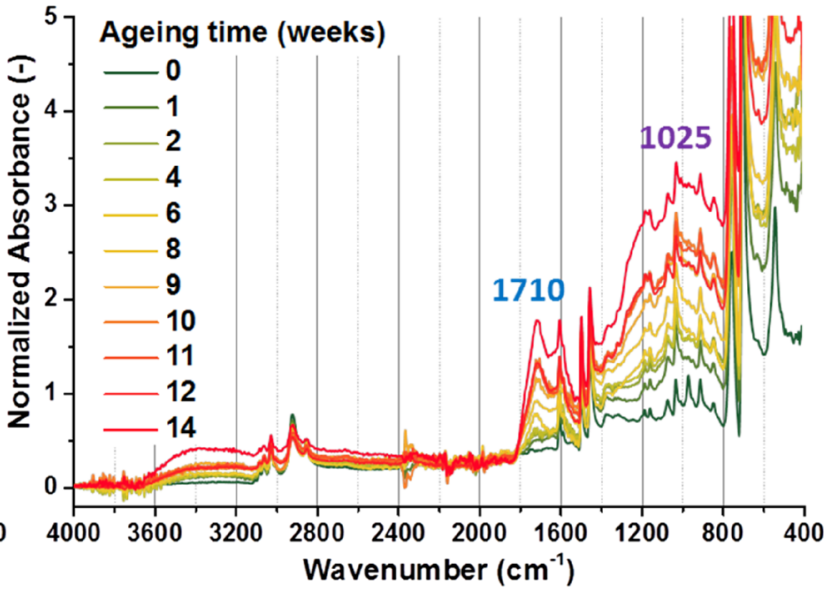

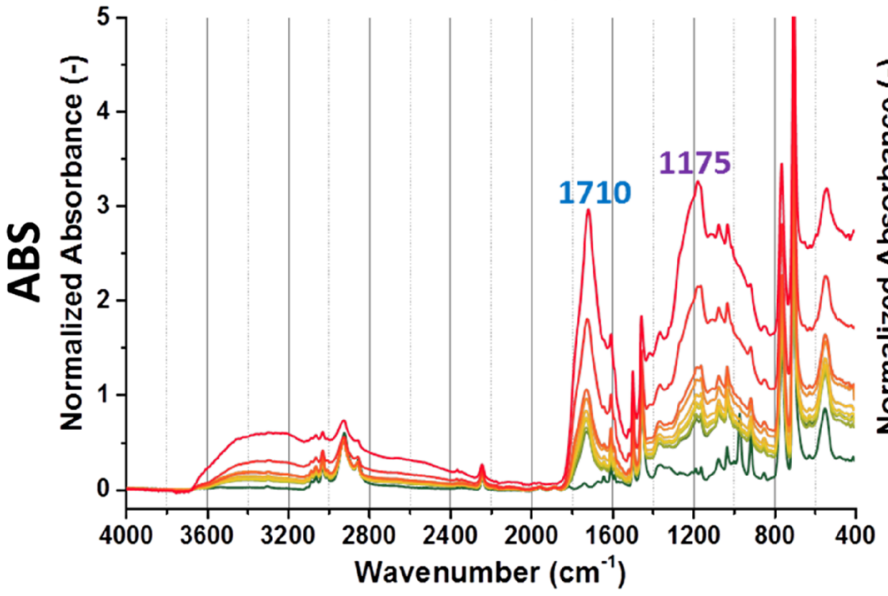

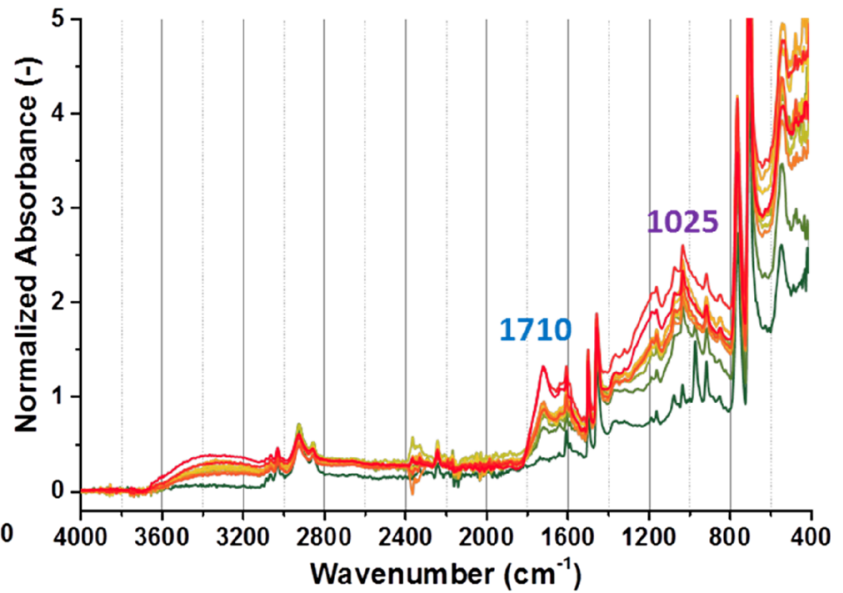

Fig. 8 FTIR-ATR spectra of HIPS \& ABS plates after natural \& accelerated photo-ageing—only aged side analyzed—color indicates ageing durations - spectra normalized on the $1452 \mathrm{~cm}^{-1}$ peak height

More visible on Fig. 9, $\mathrm{C}=\mathrm{O}$ stretching is shown through the large peak culminating at $1710 \mathrm{~cm}^{-1}$. This rather large signal for a simple carbonyl group is the result of the convolution of several peaks linked to several saturated and conjugated carbonyl species very well described in the literature [42, 43]: carboxylic acid, esters, lactones, anhydrides, ketones, aldehydes, ... Whereas a peak at $1710 \mathrm{~cm}^{-1}$, associated to acids, stands out in artificially aged samples, the carbonyl band is more homogenous in naturally aged samples. This is coherent with acid $\mathrm{O}-\mathrm{H}$ bonds being more marked in accelerated weathering. Framed in blue on Fig. 9, the peak at $965 \mathrm{~cm}^{-1}$ is associated to vinylic $\mathrm{C}-\mathrm{H}$ out-of-plane deformation and is specific to the PB phase. The $910 \mathrm{~cm}^{-1}$ peak is associated to the same vibration but also the aromatic C-H deformation of PS or SAN [43], thus visible on their respective spectra. Consequently, this peak can decrease and then stabilize without disappearing [68]. The $965 \mathrm{~cm}^{-1}$ peak disappears at first measures, 2 days in accelerated ageing, 1 week in natural, similarly to what Santos et al. found [67]. It is in concordance with the fact that PB is the prime target of photooxidation within HIPS or ABS, as very often reported in the literature $[37,38,60]$.

PS, SAN and ASA ageing spectra are also shown on Fig. 9. Whereas yellowing was rapidly seen on all of them, infrared oxidations marks appeared lately, especially for SAN where they are hardly unnoticeable, indicating that acrylonitrile brings chemical resistance to the matrix. It shows that color changes are, in this case, more sensitive than FTIR-ATR. It is worth noting that butyl acrylate rubber also degrades and can also initiate ageing as ASA spectrally ages more than SAN. However, ASA oxidation is delayed and moderate compared to ABS and HIPS where carbonyl formation is almost immediate. It corroborates the fact that $\mathrm{PB}$ initiates the matrix oxidation as its absence hindered this phenomenon [37, 42].

Similar to the methodology proposed by Scaffaro et Maio [69], spectra were also performed on a few unexposed faces to check potential oxidation diffusion. Figure 10 shows that spectra of rear sides are very similar to unaged samples, as aspect. Nevertheless, the PB peak at $965 \mathrm{~cm}^{-1}$ has notably 
Accelerated

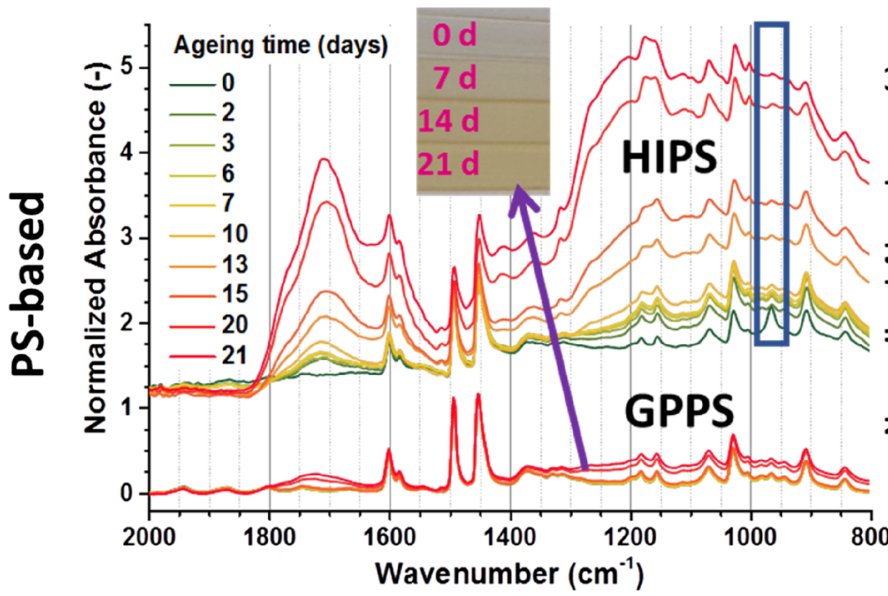

Natural

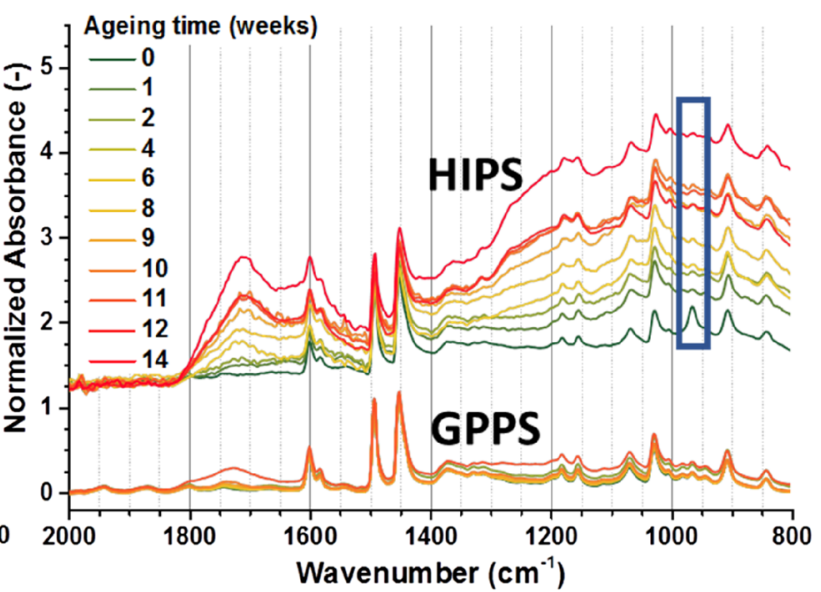

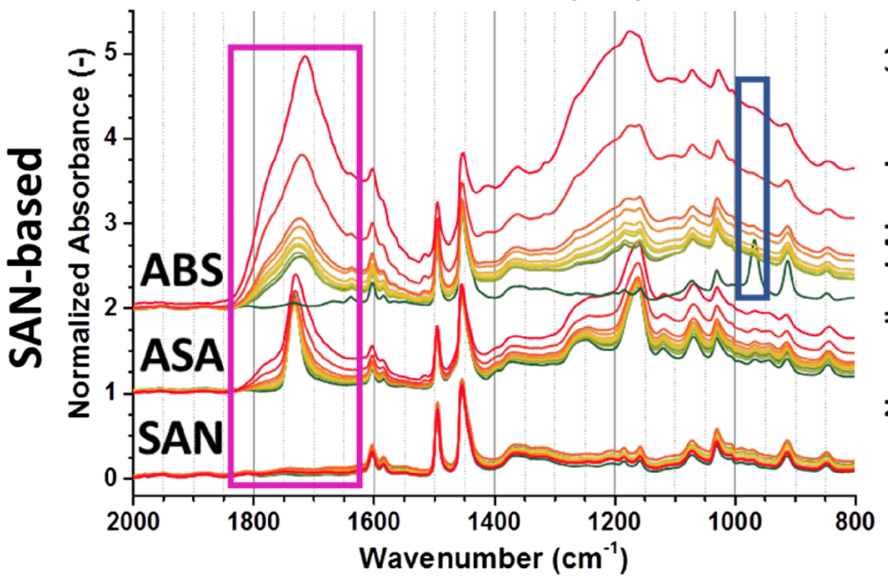

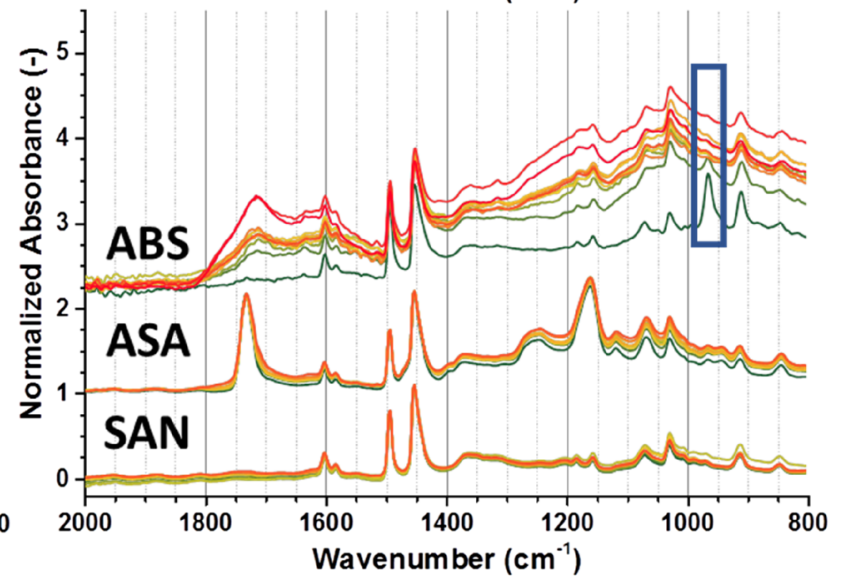

Fig. 9 FTIR-ATR spectra of aged PS, HIPS, SAN \& ABS samples in accelerated and natural conditions-zoom on $2000-800 \mathrm{~cm}^{-1}-\mathrm{spectra}$ normalized on the $1452 \mathrm{~cm}^{-1}$ peak height—-blue frame on PB peak, pink frame for integration zone of Fig. 10

disappeared, totally for HIPS, partially for ABS. However, measures at core (by cutting samples) display intact $\mathrm{PB}$ peaks. This shows that the unexposed face was subject to degradation as well, but independently from the exposed face since the core is preserved. Especially for outdoor exposure, rear sides are also exposed to light, through secondary sources by reflection. It can be assumed that this indirect irradiation is devoid of most UV light. However, PB is reportedly sensible to the visible range [70, 71], explaining its disappearance from the surface. For accelerated ageing, thermooxydation $[47,72]$ is also a conceivable explanation as temperature is rather elevated.

The carbonyl index, the carbonyl peak area normalized to a reference peak, is often used to monitor polymer ageing $[16,60,73]$. Here, integration was made from 1821 to $1649 \mathrm{~cm}^{-1}$ on spectra normalized according to the 1452 peak height.

Figure 11 shows its evolution. As spectra already hinted, oxidation is way harsher with PB reinforced materials. Unexposed face measurements, represented by hollow squares, show that oxidation is negligible on rear side, especially for ABS. As seen on Fig. 8, three weeks of accelerated ageing in applied conditions were harsher than three months of natural ageing. In every case, carbonyl index evolution showed three stages: a first rise on first two or three points, stabilization then a second harsher rise until the end. This can be explained by the competition of the numerous different chemical mechanisms which occurs within the polymer and generates carbonyl species at different stages of their process [42]. Unfortunately, these figures clearly show that strong further degradations are to come, out of the scope of the present study.

\section{Reprocessing Photodegraded Material—“Recycling"}

Further Coloration Through Extrusion Figure 12 shows pictures of colorations observed before and after "recycling" of aged material. This picture and further measurements were made on aged plates and injected dogbones, separated by the cutting mill/extruder/injection press steps. Coherently 


\section{Accelerated}
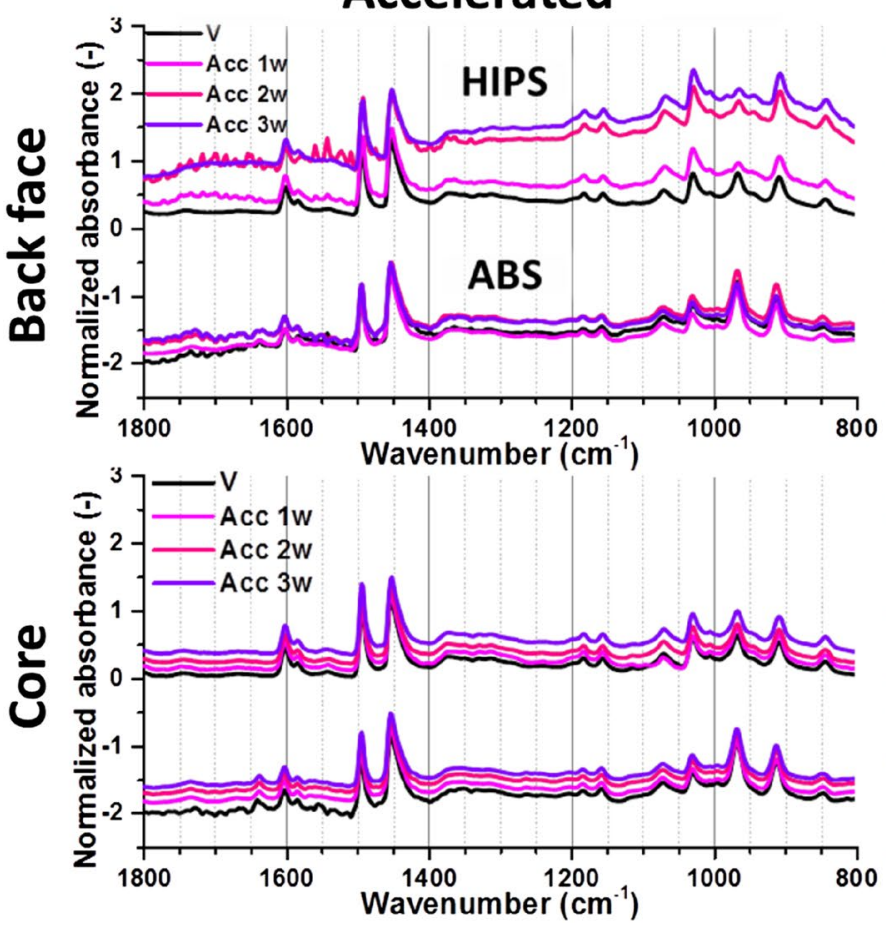

Natural
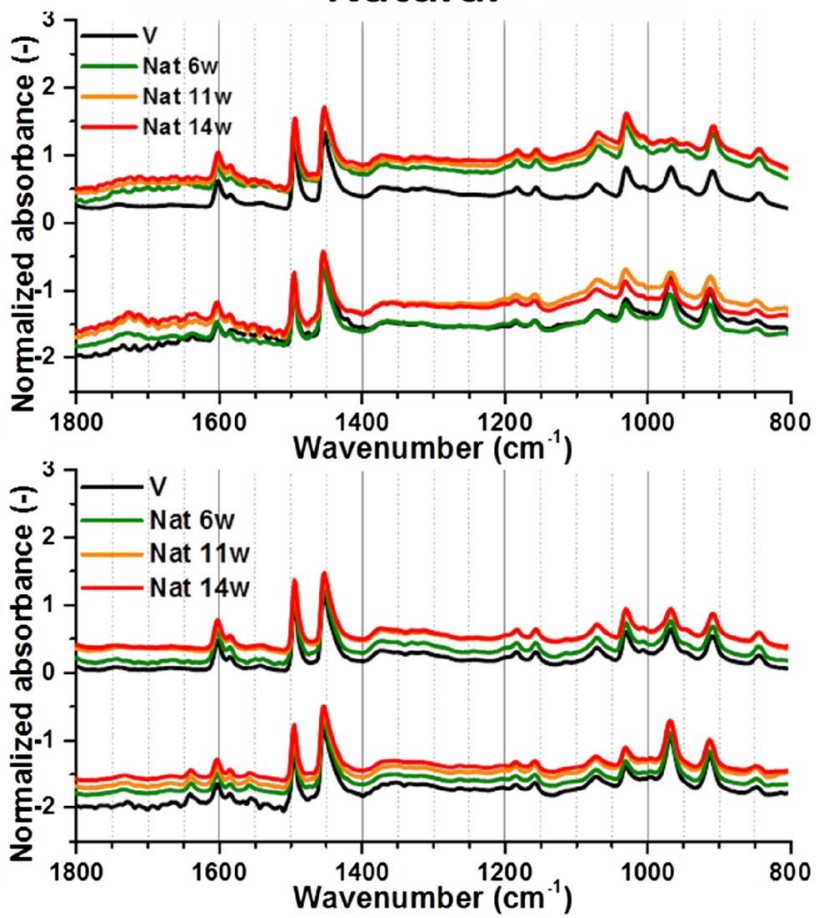

Fig. 10 FTIR-ATR spectra of unexposed faces \& cores of aged HIPS \& ABS plates in accelerated and natural conditions-zoom on 1800$800 \mathrm{~cm}^{-1}$ — spectra normalized on the $1452 \mathrm{~cm}^{-1}$ peak height
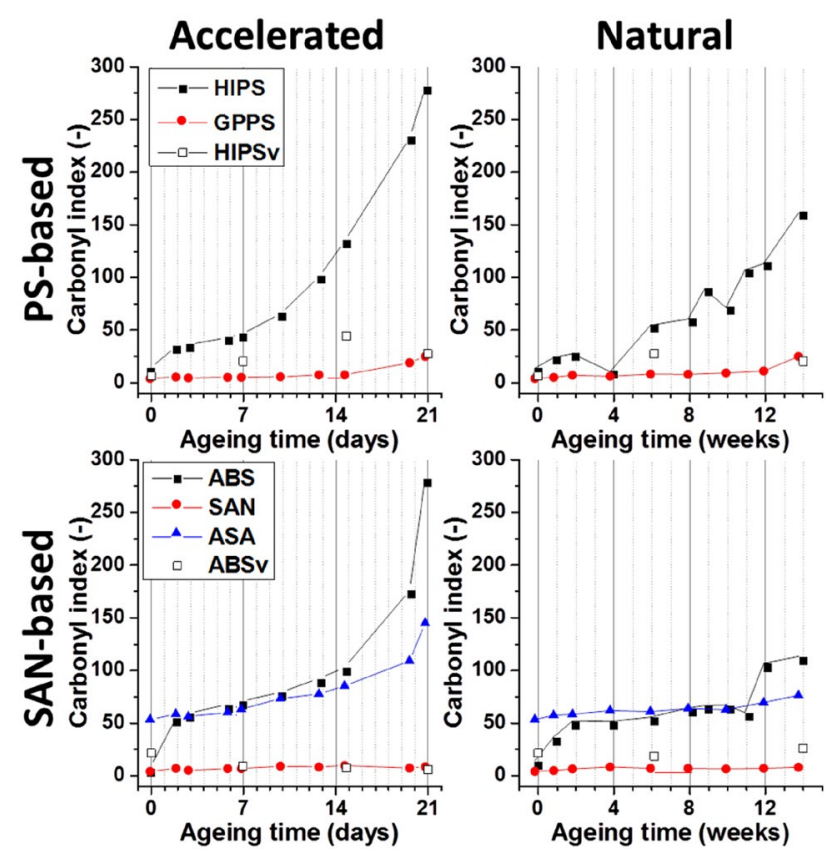

Fig. 11 Carbonyl index evolution during natural and accelerated ageing of HIPS and ABS-integration made from 1821 to $1649 \mathrm{~cm}^{-1}$ on spectra normalized according to the 1452 peak height-HIPSv and ABSv refer to measures made on unexposed face

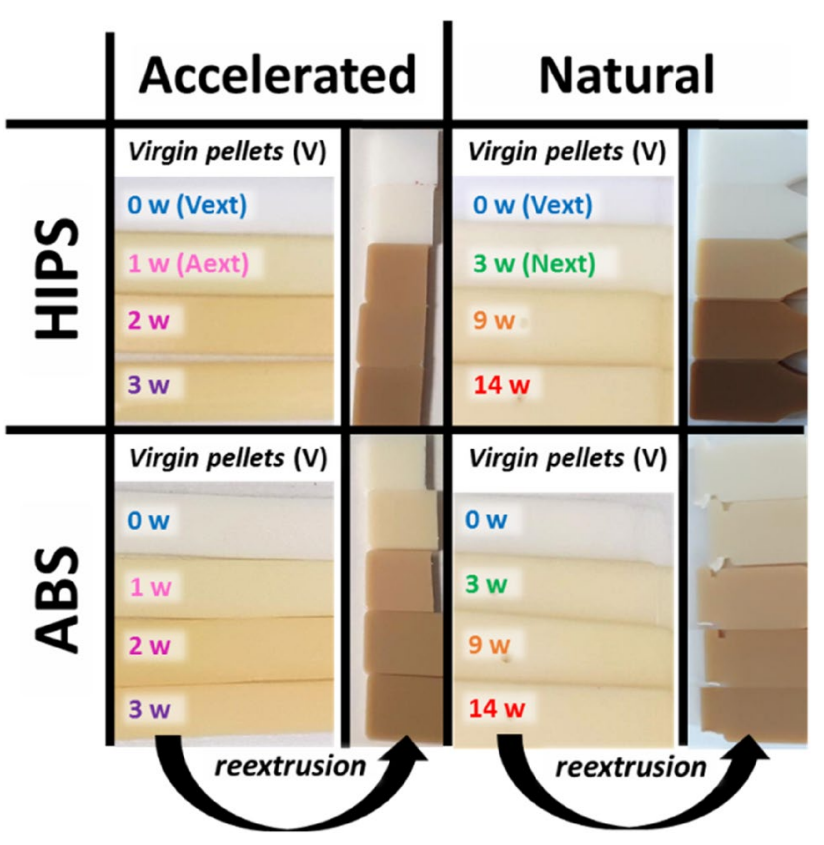

Fig. 12 Coloration through extrusion of photo-oxidized materialpictures of aged polymer plates and corresponding injected dogbones-first dogbones are produced from direct injection of pristine pellets 
to applied thermomechanical stress conditions, tint changes were mainly visually witnessed during the extrusion step. After recycling, coloration is way harsher and, in the case of naturally aged HIPS, shades between batches are more marked.

Also, while the staining was only superficial after plates weathering, reported below $70 \mu \mathrm{m}$ [43], coloration after extrusion, and even more after injection, is homogenous in the bulk. Unaged samples, which went through the same process (plate injection, cutting mill, extrusion, dogbone injection) display colors closer to samples directly injected from pellets, namely virgin material. This proves that weathered material was subject to further degradations within extrusion because of shearing and temperatures that induced strong reactions of present oxidized species, especially hydroperoxides [42]. However, color differences along ageing and after recycling, especially for artificial ageing, are too subtle to be discussed visually only. Hence, photometry measurements and associated colorimetry calculations were performed to get a better assessment of suspected evolutions. Figure 13 shows associated reflectance spectra in the visible range. Black curves, representing virgin samples, show that ABS partially absorbs below $450 \mathrm{~nm}$, in the blue range, explaining its cream color. After re-extrusion, HIPS yellowed a little whereas ABS darkened as the whole curve went down. These behavior differences could be caused by acrylonitrile presence which enables faster and further conjugation and thus higher absorptions [44, 74]. During both accelerated and natural ageing (dash lines), both materials yellowed as their reflectance were strongly diminished on the first tens of nm. After recycling, whole curves are lowered, explaining their darkened and brownish shades. This hints that
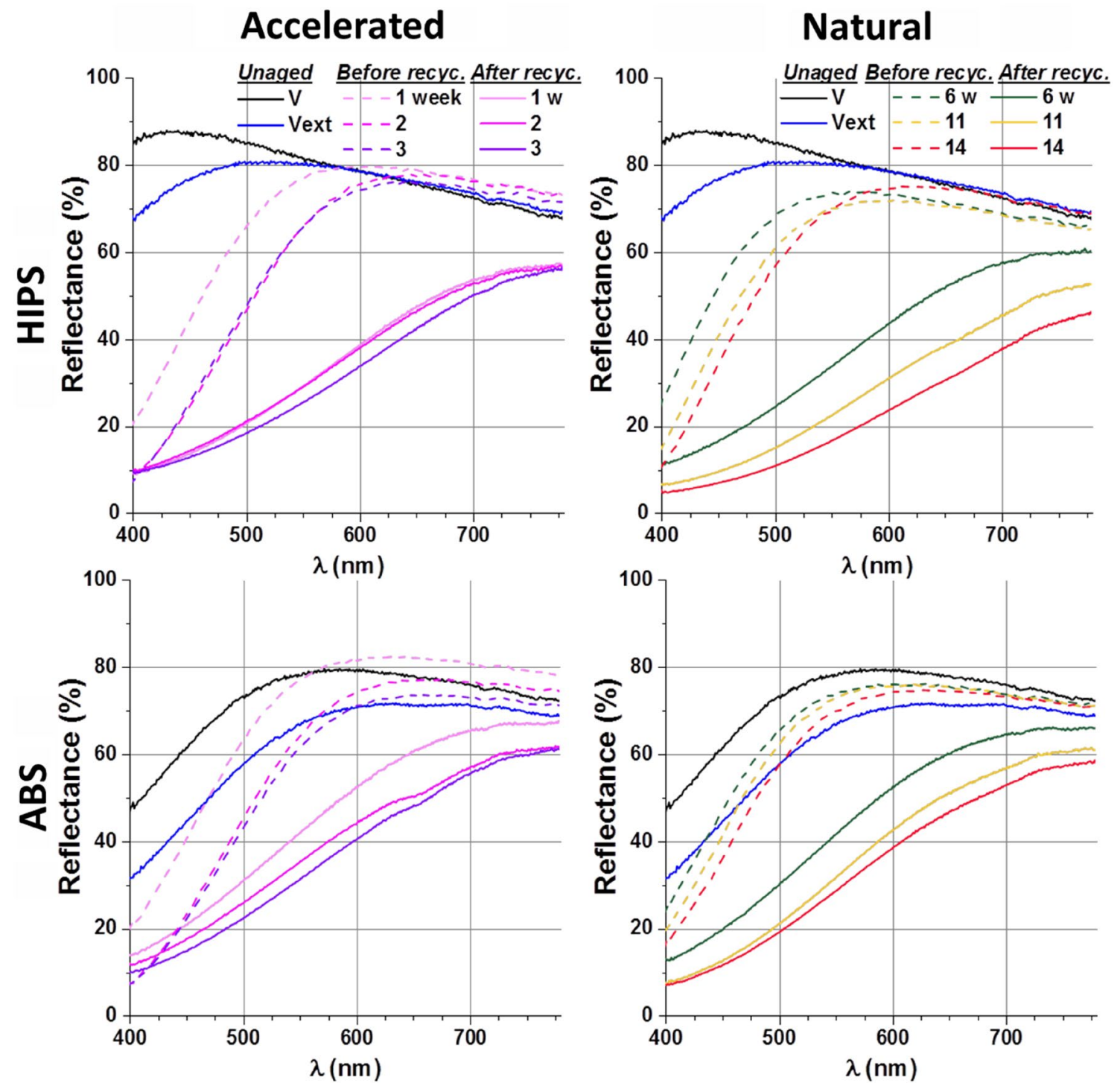

Fig. 13 Reflectance spectra in the visible range-HIPS and ABS—Accelerated and natural ageing — before and after ageing 


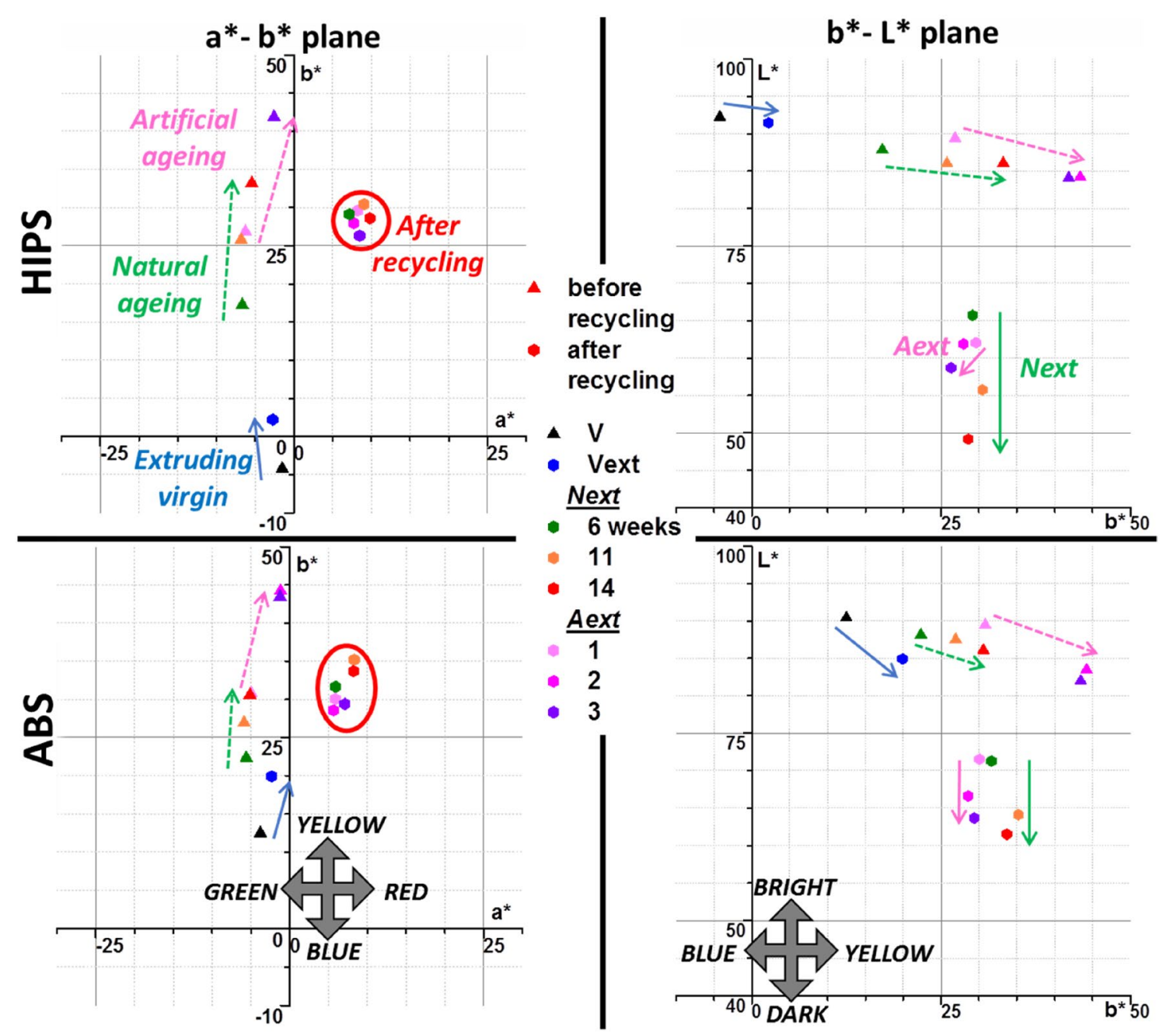

Fig. 14 Projections on the $a^{*}-b^{*}$ and $b^{*}-L^{*}$ planes of aged samples-color associated to ageing degree and shape to before/after recycling

conjugations are far more developed, in terms of involved bonds and in terms of volume concentration.

Figure 14 show projections of CIELab values in the $\mathrm{a}^{*}-\mathrm{b}^{*}$ (left-handed) and $\mathrm{b}^{*}-\mathrm{L}^{*}$ planes (right-handed) to simplify modifications visualisation. Scales were chosen equally for each parameter. It appears clearly that modifications along $\mathrm{a}^{*}$, described as evolving on a green-red axis, are rather weak. When considering starting points, HIPS is more impacted by photodegradation than ABS, especially after recycling. This is coherent with infrared results presented previously. Two "paths" can be seen on these projections: one path is along $b^{*}$ that one could call "yellowing", associated to photodegradation and accompanied by a slight decrease of $\mathrm{L}^{*}$; the other path is principally along $\mathrm{L}^{*}$ that one could call "darkening", associated to recycling photodegraded material. The slight increase along $\mathrm{a}^{*}$, thus toward red, matches with the more brownish tint of reprocessed samples. Coherently with Fig. 13, unaged HIPS went along the "yellowing path" during re-extrusion whereas ABS went along the other one. Whereas yellowing is more important during artificial ageing, darkening is stronger after recycling naturally weathered material, hinting for stronger degradation. This apparent discrepancy could be due to differences in ageing depths. Accelerated ageing could have rapidly generated an effective protective layer of oxidized material which limits oxygen diffusion and/or UV transmission [43, 44], especially in view of weak reflectance in low wavenumbers seen on Fig. 13. Moreover, Audouin et al. [75] showed by combining Fick diffusion models and chemical kinetics laws that the thickness of oxidized layer was of the same order of magnitude of the ratio of the diffusion coefficient and pseudo-first-order rate constant. Since accelerated ageing leads to an increase of this second parameter, oxidation is inevitably shallower. In other words, oxygen does not have the time to migrate deeply because surface layers are too reactive towards it and consume it rapidly. As a shallower stock of oxidized species is generated compared to natural ageing, further degradations through extrusion are 


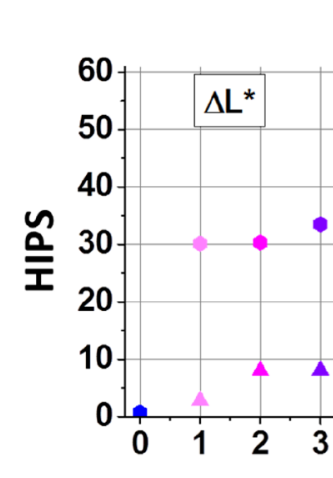

\section{Accelerated}
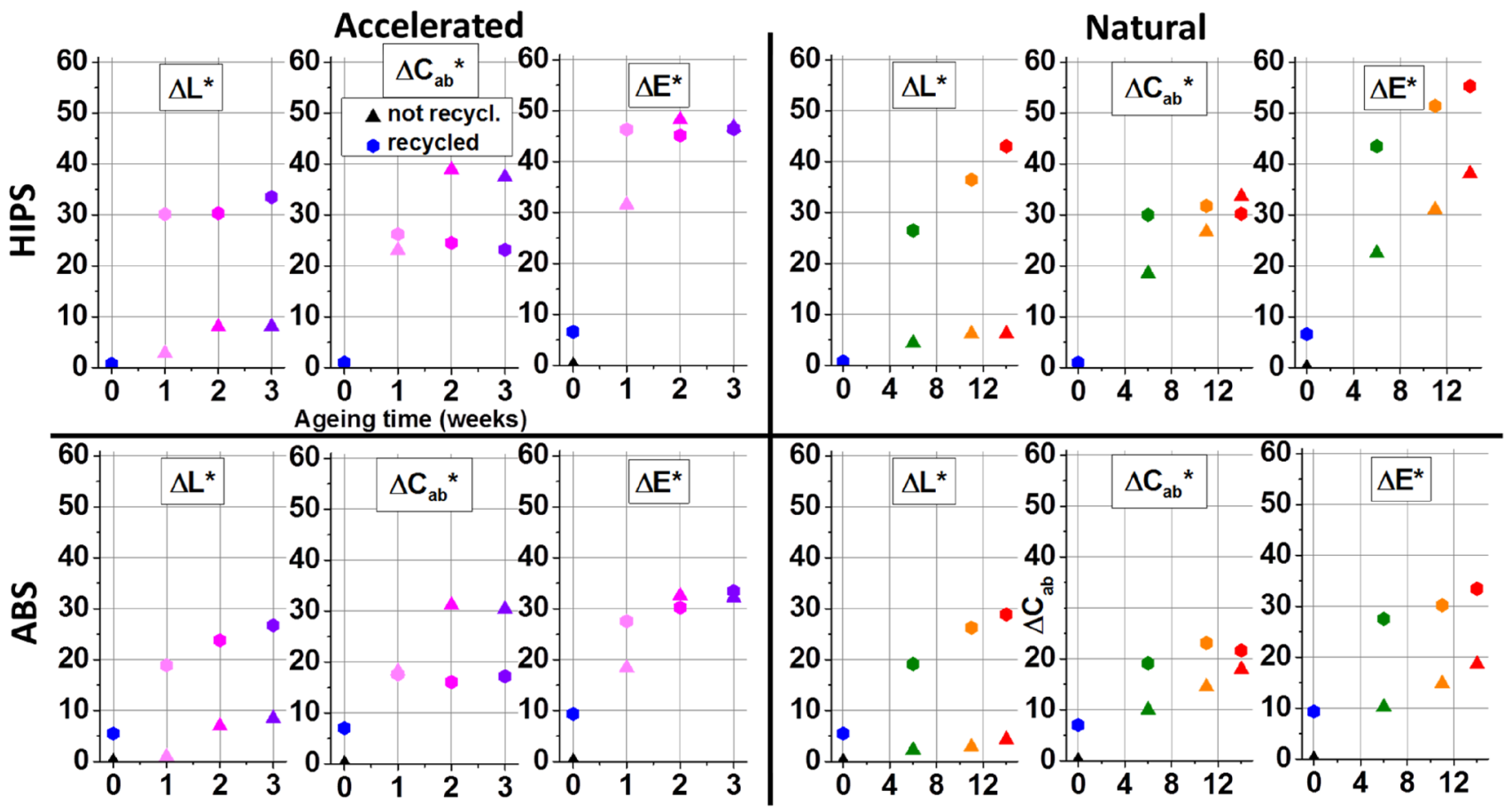

Fig. $15 \Delta \mathrm{L}^{*}$ (lightness difference), $\Delta \mathrm{C}_{\mathrm{ab}} *$ (chroma difference) and $\Delta \mathrm{E}^{*}$ (color difference, norm of the two previous ones) plots- HIPS \& ABS-Accelerated \& Natural ageing_ "V" batches (no ageing, no extrusion) taken as references (Color figure online)

limited. It is also corroborated by the smaller differences between artificial batches compared to differences between natural ones. Finally, Searle et al. [71] found a "bleaching" effect from 380-525 nm irradiation which supposedly lead to conjugated species decomposition. As UVA-340 lamps used in the present study emit mainly from 320 to $380 \mathrm{~nm}$ [64], these yellow-colored species are preserved. Eventually, this would mean that either if accelerated ageing leads to stronger yellowing, material is globally less altered.

Figure 15 shows the evolution of several parameters with ageing time and recycling: $\Delta \mathrm{L}^{*}$, the "lightness difference" calculated by $\mathrm{L}^{*}$ differences in absolute values; $\Delta \mathrm{C}_{\mathrm{ab}}{ }^{*}$, the "chroma difference", calculated as the norm of $\mathrm{a}^{*}$ and $\mathrm{b}^{*}$, thus it is the distance from the reference to the considered point in the $a^{*}-b^{*}$ plane; $\Delta \mathrm{E}^{*}$, the "color difference", the norm of $\mathrm{L}^{*}, \mathrm{a}^{*}$ and $\mathrm{b}^{*}$, thus the norm of $\Delta \mathrm{L} *$ and $\Delta \mathrm{C}_{\mathrm{ab}} *$. "V" batches, virgin pellets directly injected into dogbones, were used as references for calculation and are thus at null values. These plots confirm several elements seen before: unaged ABS is more marked and differently marked by recycling compared to HIPS; ageing impacts mainly $\mathrm{b}^{*}$ (thus $\Delta \mathrm{C}_{\mathrm{ab}}{ }^{*}$ here) whereas recycling impacts mainly $\mathrm{L}^{*}$ (thus $\Delta \mathrm{L}^{*}$ here). $\Delta \mathrm{L}^{*}$ milder evolutions in accelerated ageing is clearer. For both HIPS and ABS, $\Delta \mathrm{C}_{\mathrm{ab}}$ * behavior toward recycling is different depending on ageing conditions. Whereas it decreased with reprocessing after accelerated ageing, it increased after natural ageing. It is due to both initial colorations being weaker in natural ageing and final ones being lightly stronger after recycling. Consequently, evolutions of $\Delta \mathrm{E}^{*}$, sometimes used to monitor discoloration during polymer ageing [74, 76], does not display significant changes in accelerated ageing. $\Delta \mathrm{E}^{*}$ evolutions in natural ageing seem to demonstrate that recycling "just" shifts values up. However, it is more complicated as $\Delta \mathrm{L}^{*}$ increments from recycling steadily increase whereas $\Delta \mathrm{C}_{\mathrm{ab}} *$ increments decrease. The yellowness index, which can be defined as a pondered ratio of $b^{*}$ on $L^{*}$ [77], is sometimes used to monitor polymer discoloration $[67,78]$. It could be suitable here but not as informative as disjoint evolutions.

\section{Infrared Assessment of Recycled Samples}

FTIR-ATR of the dogbones from recycled materials (Fig. 16) revealed no visible difference from unaged material, even with analysis made on orthogonal cuts. Neither oxidation marks nor PB disappearance are observed. Whereas they were highly concentrated at the surface for photodegraded plates, they are here supposedly diluted enough to get unnoticeable in FTIR. Also, whereas color was mild before recycling because only less than $100 \mu \mathrm{m}$ contributed, the whole bulk participates in this case. Boldizar et Möller [60] also observed lowered carbonyl index after reprocessing thermally aged ABS. This also shows a higher sensibility of 
Fig. 16 FTIR-ATR spectra of recycled dogbones (surface and core) compared to virgin references-heights normalized on aromatic $\mathrm{C}-\mathrm{H}$ peak at $750-760 \mathrm{~cm}^{-1}$
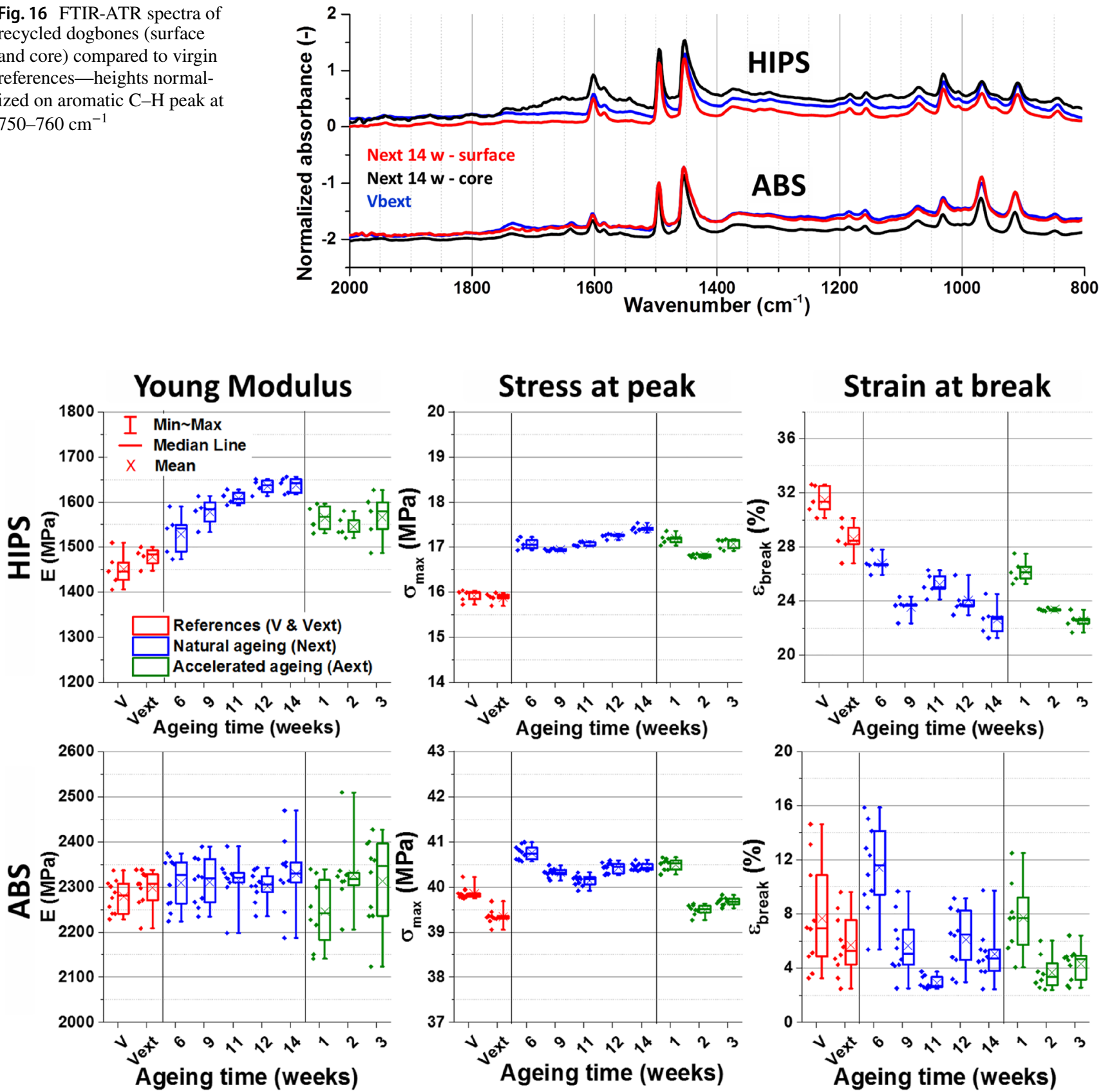

Fig. 17 Traction test data boxplots-Young Modulus, Stress at peak \& Elongation at break-whiskers correspond to min-max, box limits to quarters, mid line to median

color to chemical species formed during degradation, in comparison to infrared studies in this particular case. Especially, SAN, PS and ASA (Fig. 9, part 3.1.2.) gained a yellow color visible to the naked eye without significant FTIR spectra alteration.

\section{Impact on Mechanical Properties}

After ageing (natural or accelerated) and recycling, ABS displayed no important changes in tensile properties whereas HIPS stiffened moderately and adopts a more brittle behavior (Fig. 17). Full curves are available in supporting information. Several authors also found moderate sensitivity of ABS tensile properties towards degradation [48, 79, 80]. Grinding-extrusion itself had its effect on HIPS as the "Vext" 
batch displayed a slightly increased Young's modulus and a decreased strain at break compared to the "V" batch. Aged and recycled HIPS samples show further evolutions in the same direction. For natural conditions, the Young's modulus increased from 1475 to $1640 \mathrm{MPa}(+11 \%)$ in twelve weeks and seems to stabilize at this value. However, strain at break steadily decreases from 28 to $22 \%(-21 \%)$. Maximal stress was mainly differentiated from unaged and aged samples with a slight increase $(+6 \%$ between $\mathrm{V}$ or Vext, and first batches from 6 to 11 weeks, then up to $9 \%$ for the maximal duration). For accelerated ageing, E-modulus is roughly the same for the three batches, around $1575 \mathrm{MPa}(+7 \%)$ whereas strain at break shows an evolution comparable to natural ageing in their respective durations. Arraez et al. [72] observed very strong loss of strain at break for thermally degraded HIPS with pro-oxidant additives. They also observed increases of Young modulus and maximal stress to a lesser extent. They explained that PB has a "softening" effect, leading to lower stiffness and strongly more ductile behavior than GPPS, and thus, PB degradation leads to the progressive loss of this effect. Moreover, we could add that as PB mainly degrades by crosslinking, increasing its own modulus and maximal stress, and reducing its own strain at break. Molecular weight decrease due to chain scission is often reported as the main degradation mechanism for PS $[47,73,81,82]$. Since it is a totally amorphous polymer, it cannot go through chemicrystallization, thus, most mechanical properties shall decrease, modulus and maximal strength as well. Consequently, results presented here are probably linked to PB degradation.

However, as color, impact energies displayed more important changes on both polymers, as shown on Fig. 18. Bai et al. [79] also found reduced impact strength reduction on ABS reprocessed several times whereas its tensile properties were little modified. They associated it mainly to volatiles loss through GCMS analyses and reported PB crosslinking whereas SAN matrix remained mostly unaffected. This differs from the explanation reported above from Arraez et al. [72], which rooted HIPS loss of tensile properties to PB degradation. PB morphologies greatly differ
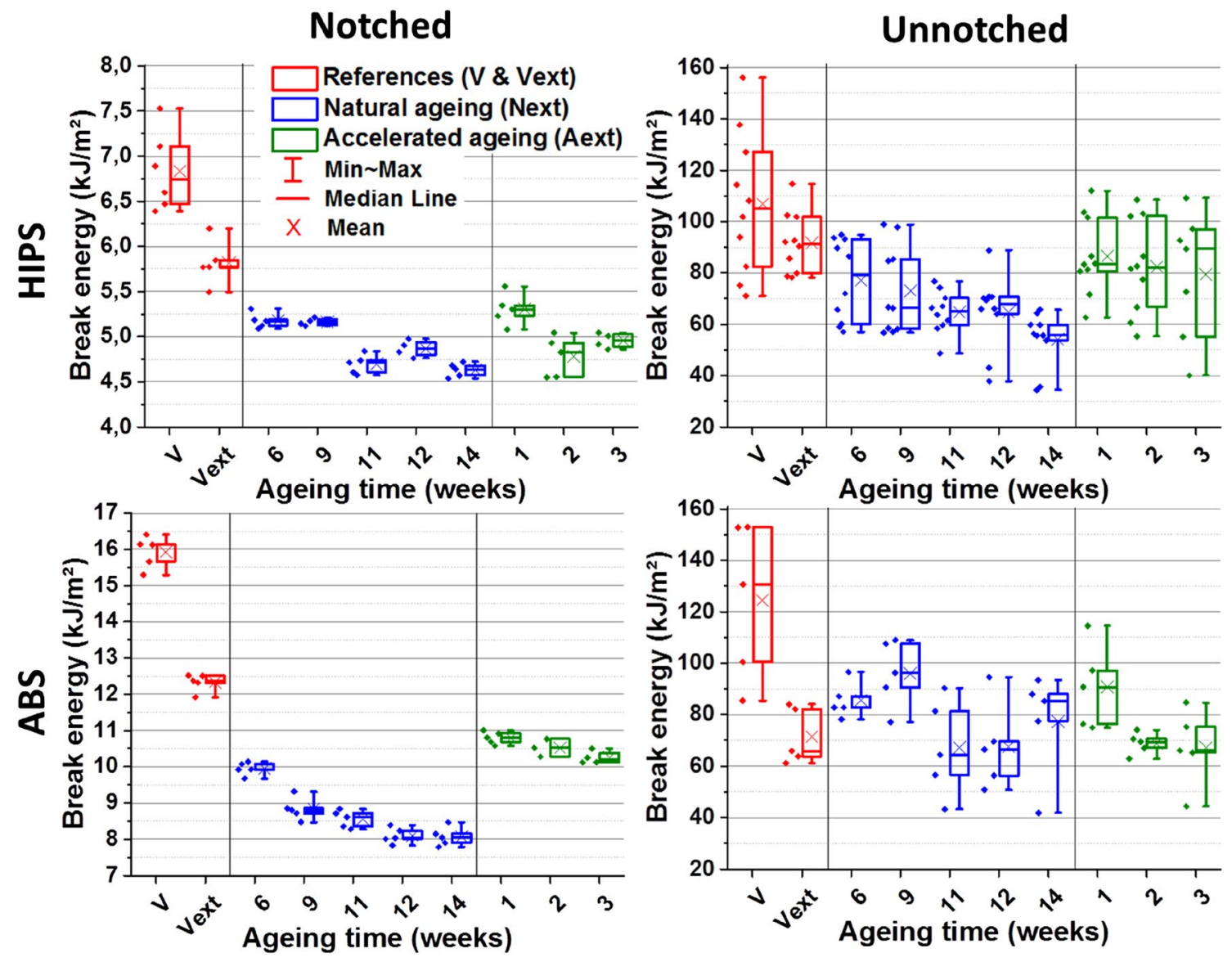

Fig. 18 Charpy impact test break energies boxplots—notched and unnotched—whiskers correspond to min-max, box limits to quarters, mid line to median 
between the two matrices, both in size and shapes [31-34]. Also, the grafting of PB to SAN during emulsion synthesis could bring more sensitivity to impact properties from SAN. However, PB could globally less degraded than in HIPS since the morphology of dispersed phase is finer within the matrix and thus less accessible to oxidation. Consequently, ABS tensile properties could be preserved as degradation is less important.

As with tensile properties, the "recycling" step alone has impacts on results, both HIPS ( -15 and $-22 \%)$ and ABS $(-10$ and $-45 \%)$ showing decreases in both notched and unnotched tests, coherently with literature about reprocessing $[79,83]$. This hints that processing conditions are not relevant for these materials, especially ABS. To temper this statement, ABS started with high impact properties. Naturally aged HIPS shows rather steadily decreases in both notched $(-17 \%$ more $)$ and unnotched tests $(-39 \%)$ whereas samples issued from accelerated only present a slighter decrease $(-13 \%$ and $-11 \%)$. ABS shows very clear trends in notched test: steadily small decrease for accelerated $(-18 \%)$ whereas it falls faster and seems to tend to an asymptote in natural conditions $(-36 \%)$. Results of unnotched samples do not show clear trends but display decreased properties $(-15$ and $-7 \%)$. Differences of results dispersion between notched and unnotched tests are easily explainable by fractures modes. Whereas notching tests promote a brittle failure mode according to the stress concentration induced by this geometry, testing unnotched samples produce a failure accompanied by an important plastic deformation where ultimate fracture became more statistical, well seen on instrumented curves, in supporting information. Tiganis et al. [79] found dramatically decreased unnotched impact properties on thermally degraded ABS whereas its notched properties were conserved. They attributed this difference on the fact that degradation is limited to the surface, which is true on most bulk materials. In our specific case, reprocessing remixes materials so the tested specimens are rather homogeneous. Thus, the notch mainly eliminates the crack initiation step and not a potential "skin effect" (term usually used for plastic transformation phenomenon but here for degradation).

Figure 19a shows conjoint evolution of break energies (expressed in $\mathrm{kJ} / \mathrm{m}^{2}$ ) issued from tensile test (areas under stress-strain curves) and unnotched Charpy impact test. Unnotched tests were chosen to enable comparison as notches strongly concentrate stress. Three decades separate solicitation speeds as Charpy impact was performed at $3.0 \mathrm{~s}^{-1}$ and tensile tests at $10 \times 1.5 \times 10^{-3} \mathrm{~s}^{-1} \mathrm{~mm} / \mathrm{min}$. The slower loading rate enables the material to develop an important elastic energy compared to impact test, which explain the high Y-intercept of $218 \mathrm{~kJ} / \mathrm{m}^{2}$ of the linear regression. The slope of 1.3 could be explained by both a better stress accommodation at lower rate and the fact that a more important volume is solicited during tensile test as the whole specimen contributes whereas mainly the face in tension opposite to that in contact with the impactor dissipates energy during Charpy's test. (a)

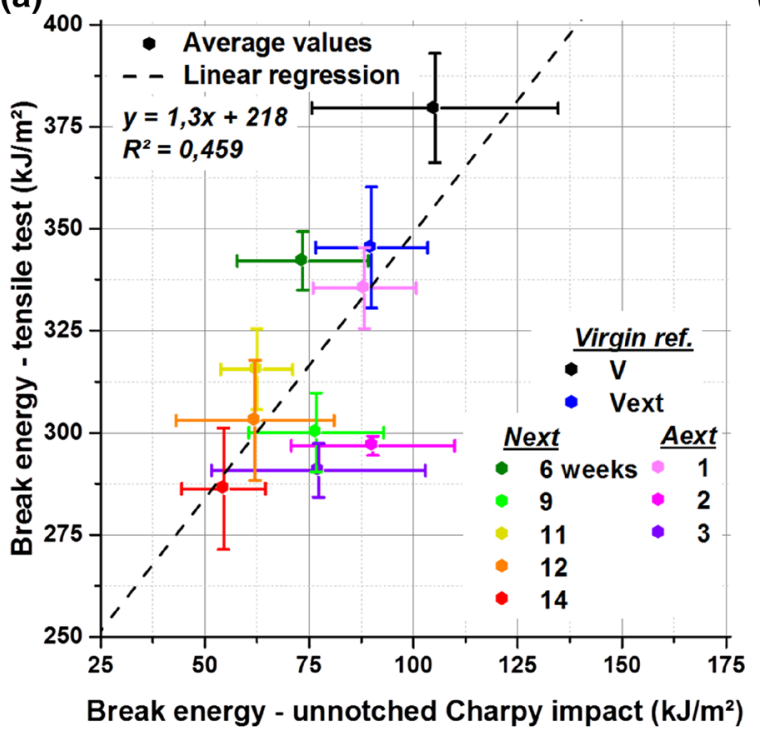

(b)

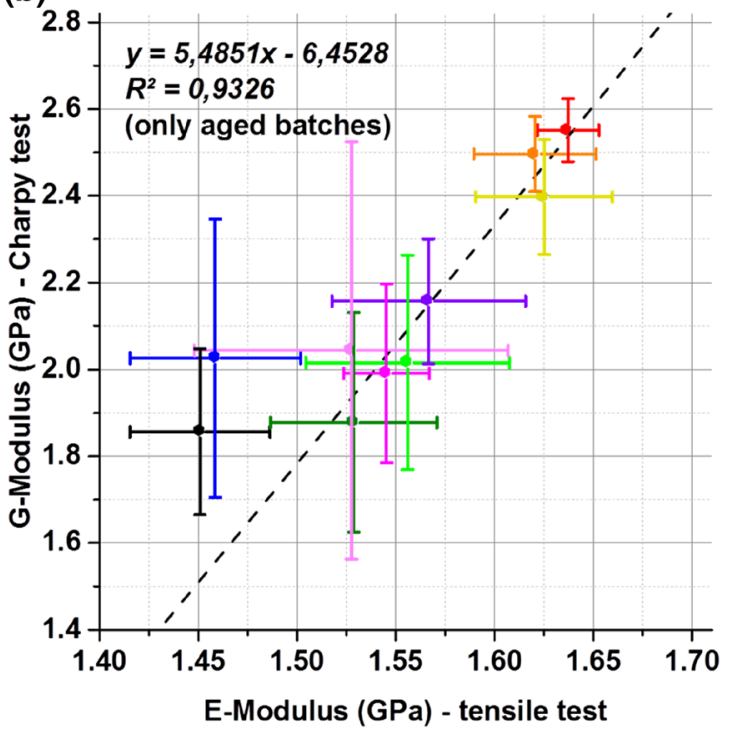

Fig. 19 a Tensile break energy at $10 \mathrm{~mm} / \mathrm{min}\left(\approx 1.7 \times 10^{-4} \mathrm{~m} / \mathrm{s}\right)$ vs unnotched Charpy impact break energy at $2.9 \mathrm{~m} / \mathrm{s}$; b G-Modulus derived from unnotched Charpy impact vs E-Modulus derived from tensile test-points represent averages and error bars standard deviations - colors correspond to ageing degree-dash lines correspond to linear regression on average values 
Figure 19b shows conjoint evolutions of flexion modulus (G-modulus) and E-modulus. E-Moduli presented here are the same as previously, calculated from tensile tests. G-modulus are calculated from instrumented unnotched Charpy impact (curves shown in supporting information) by isolating the "rising" part of the curve, from after the "kinetic peak" to the beginning of the force plateau. This part is fitted with 2 nd order polynomial and 1st order term is then used to calculate the G-modulus. As this part displays stronger slopes with ageing, it is associated to modulus rise. This is not seen in ABS curves, concordantly with its absence of E-modulus changes. Except for virgin batches, HIPS values plotted on Fig. 19b are well aligned and ranked according to their ageing degree, with natural ageing going further, as previously seen on other results. The high slope of the regression could highlight a "velocity effect" which promotes stiff behaviors with strain speed. That virgin batches are stiffer in Charpy tests than in tensile tests could be due to differences in skin/core structures after ageing as they got less viscous during specimen injection. Indeed, flexural tests are way more sensible to skin effects than tensile tests. Results showed in Fig. 18 shows that both tests are not totally switchable even in the case of HIPS where they showed very similar trends. Comparison of maximal stresses obtained in both tests was not conclusive, especially as maxima automated retrieval is tempered on instrumented Charpy impact by the important observed oscillations.

Figure 20 summarizes the main modifications of HIPS during recycling gradually aged materials. Points represent

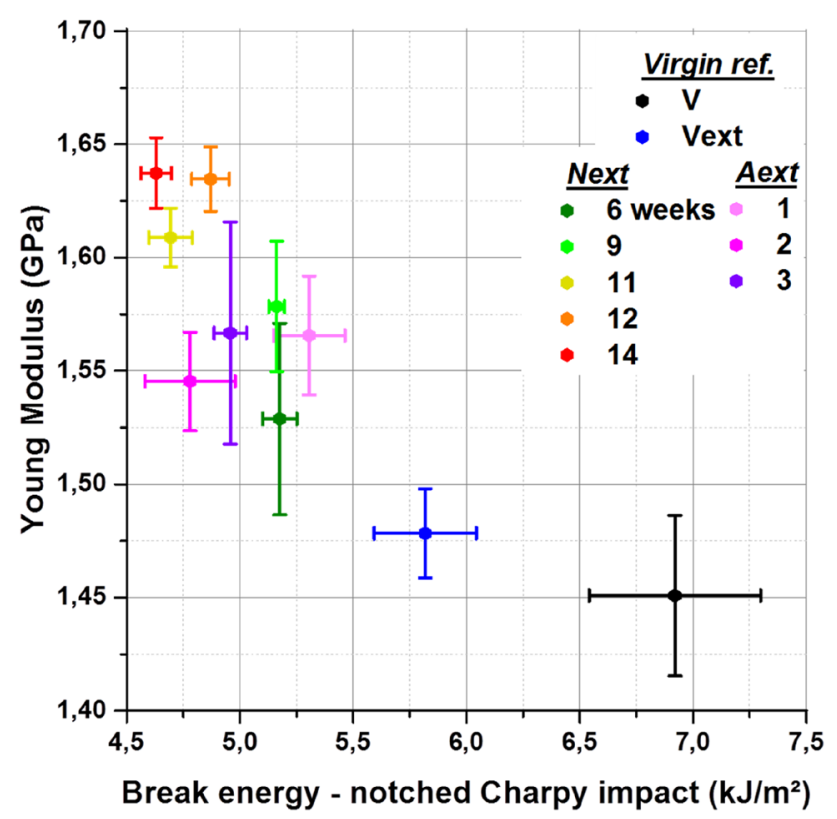

Fig. 20 Notched Charpy impact vs E-Modulus for HIPS photodegradation/recycling - points represent averages and error bars standard deviations - colors correspond to ageing degree (Color figure online) averages on the 5 specimens by batch and by test whereas error bars correspond to associated standard deviations. Whereas reprocessing unaged material mainly impaired impact properties, reprocessing of naturally weathered materials had more influence on E-modulus, leading to increased values. Conversely, recycled samples issued from accelerating ageing do not display any Young's modulus evolution and notched Charpy break energies differences are not very significant considering the dispersion of experimental data. These different behaviors with or without ageing could indicate that PB degradation firstly impairs impact resistance, then causes an increase of Young's modulus. Another explanation could be linked to the dual nature of HIPS. It can be assumed from photometry measures that the PS matrix is more severely attacked after reprocessing of photodegraded materials than virgin materials. PB can be rapidly degraded during extrusion and impairs mainly impact resistance. Instead, PS can be noticeably degraded mainly after PB initiation, thus, by extruding after photooxidation. Only then, tensile properties could be importantly changed. However, since chain scission is the main reported mechanism for PS, it seems not to govern the mechanical properties since modulus increases here along ageing and chemicrystallization was never reported in PS. A parallel and complete study of PS alone seems necessary to answer these questions correctly.

\section{Conclusions}

These works focused on evaluating the impact of mechanically recycling differently photodegraded styrenic materials on mechanical properties and coloration. In this purpose HIPS and ABS were aged in both natural and artificial conditions at different durations. As a matter of fact, important surface yellowing and strong marks of oxidation in FTIR were observed.

Comparison of HIPS to GPPS, and of ABS to SAN, during both natural and artificial ageing, highlighted the initiator role of PB [42], the impact modifier present in HIPS and ABS [29], as its absence delayed and slowed down oxidation observed in FTIR. During re-extrusion of HIPS and ABS, a far stronger coloration was observed in the bulk, especially for previously photodegraded material in both natural and artificial conditions. While evolution of coloration during weathering was mainly along $b^{*}$, a yellow indicator, a secondary coloration appeared after recycling and was darker and "browner", strongly along L*. Even though HIPS started with a rather white color, it went through more severe changes than ABS which already had a light yellowish color at start, in concordance with stronger oxidations seen in FTIR. Differences in coloration behaviors between 
HIPS and ABS were even more severe after reprocessing these photodegraded materials.

Mechanical tests showed that both ABS and HIPS became more fragile after reprocessing in all cases as it can expected from PB degradation [72, 79, 83]. However, recycling of previously aged material strongly increases this effect. Whereas ABS only lost impact resistance [79], HIPS tensile behavior was also affected [72], with slight E-modulus and maximal strength increases and strain at break decrease. Differences in PB morphologies and grafting to the matrices [30], especially along ageing and reprocessing, could be the root of these differences, leading to main loss of its impact reinforcement or its "softening" effect. That ABS is more resistant than HIPS towards ageing can be explained by both a stronger chemical resistance brought by acrylonitrile. Coherently, GPPS showed oxidation during artificial and natural ageing whereas SAN did not. Another explanation to ABS stability could be the sacrificial role of $\mathrm{PB}$ as it is present in greater quantities within $\mathrm{ABS}[35,36]$.

Whereas accelerated ageing led to stronger and deepening coloration and spectral alterations, mechanical properties changes and further colorations after recycling were stronger with natural ageing. This could be linked to a stronger but shallower oxidation within artificially aged materials as a protective layer forms rapidly, absorbing UV light and hampering oxygen diffusion $[43,44]$. Also, absence of visible light in applied accelerated ageing could lead to less severe chemical alteration.

It should be emphasized that for industrial conditions and real waste, without even considering polymer and non-polymer impurities as fillers and additives, different grades (thus different molecular weights at start) of material at different ageing levels are mixed together. Variety of antioxidants, pigmentations and accidently pro-oxidative species (as flame retardants) strongly complicate the matter. This study shows that even relatively small quantities of phototdegraded material (reportedly $<70 \mu \mathrm{m}$ on $4 \mathrm{~mm}$ ) can "contaminate" a whole batch in a certain measure, due to the presence of reactive species as hydroperoxides, depending which properties are sought (modulus or impact resistance). In this point of view, it could be preferable to put aside very aged materials if the used sorting technology permits it, as NIR-HSI.
Adapting processing conditions to milder thermomechanical stress and working on re-stabilization by incorporation of anti-oxidants are also important to prevent further oxidation.

Acknowledgements The authors would like to thank Benjamin Gallard, Robert Lorquet, Alexandre Cheron, Romain Ravel and Alain Diaz for technical support, respectively for polymer processing, spectroscopy, mechanical and rheological testing, accelerated ageing and handiwork. Pierre-Alain Ayral, Brahim Mazian and Jean-Francois Didon-Lescotthe from the Saint-Christol-lez-Alès weather station for their support in meteorological monitoring. Solange Madec, Danièle Larroze, Lydie Baroni and Sylvie Beuhorry are acknowledged for administrative support. Pellenc ST and Suez are gratefully acknowledged for partnership in this work.

Funding This work was supported by BPI France via the FUI 20 (Fonds Unique Interministériel) grant and Suez internship funding.

\section{Appendix}

See Figs. 21, 22, 23, and 24.

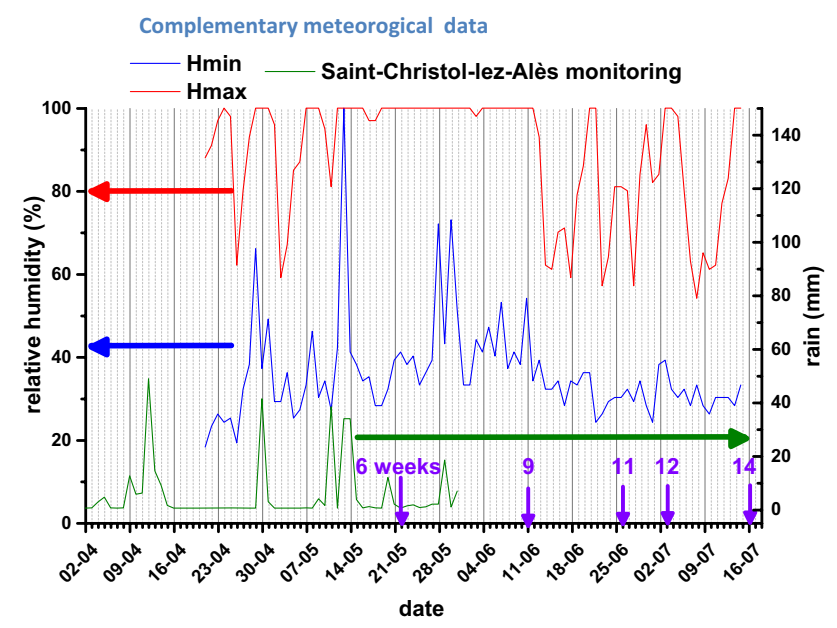

Fig. 21 Relative humidity and rain monitoring on natural ageing period-purple arrows correspond to ageing durations for mechanical recycling 


\section{Tensile tests full curves}
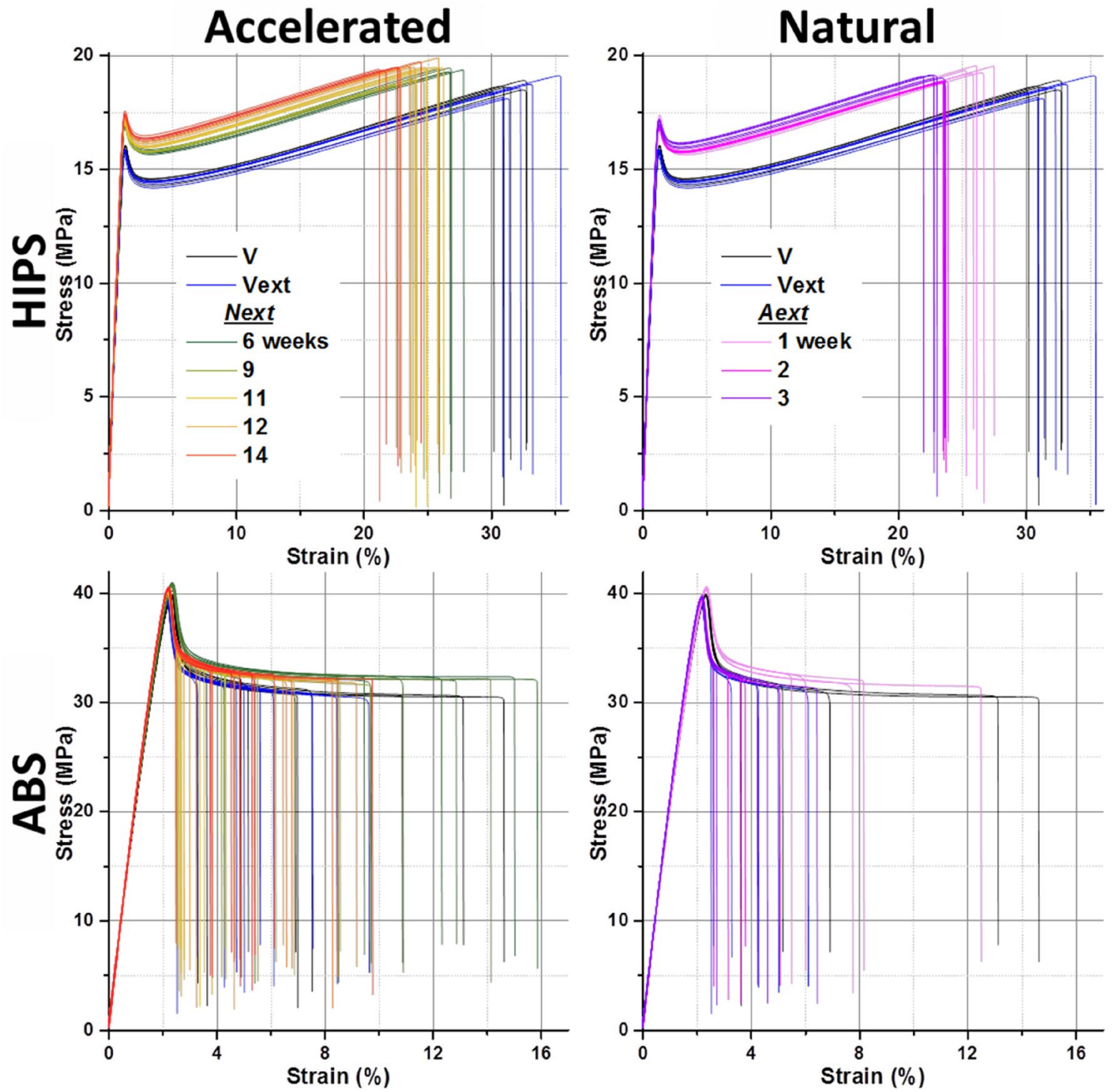

Fig. 22 Tensile tests curves-ISO 527, $10 \mathrm{~mm} / \mathrm{min}$ - accelerated and natural ageing — 5 specimens/batch for HIPS, 10 for ABS 


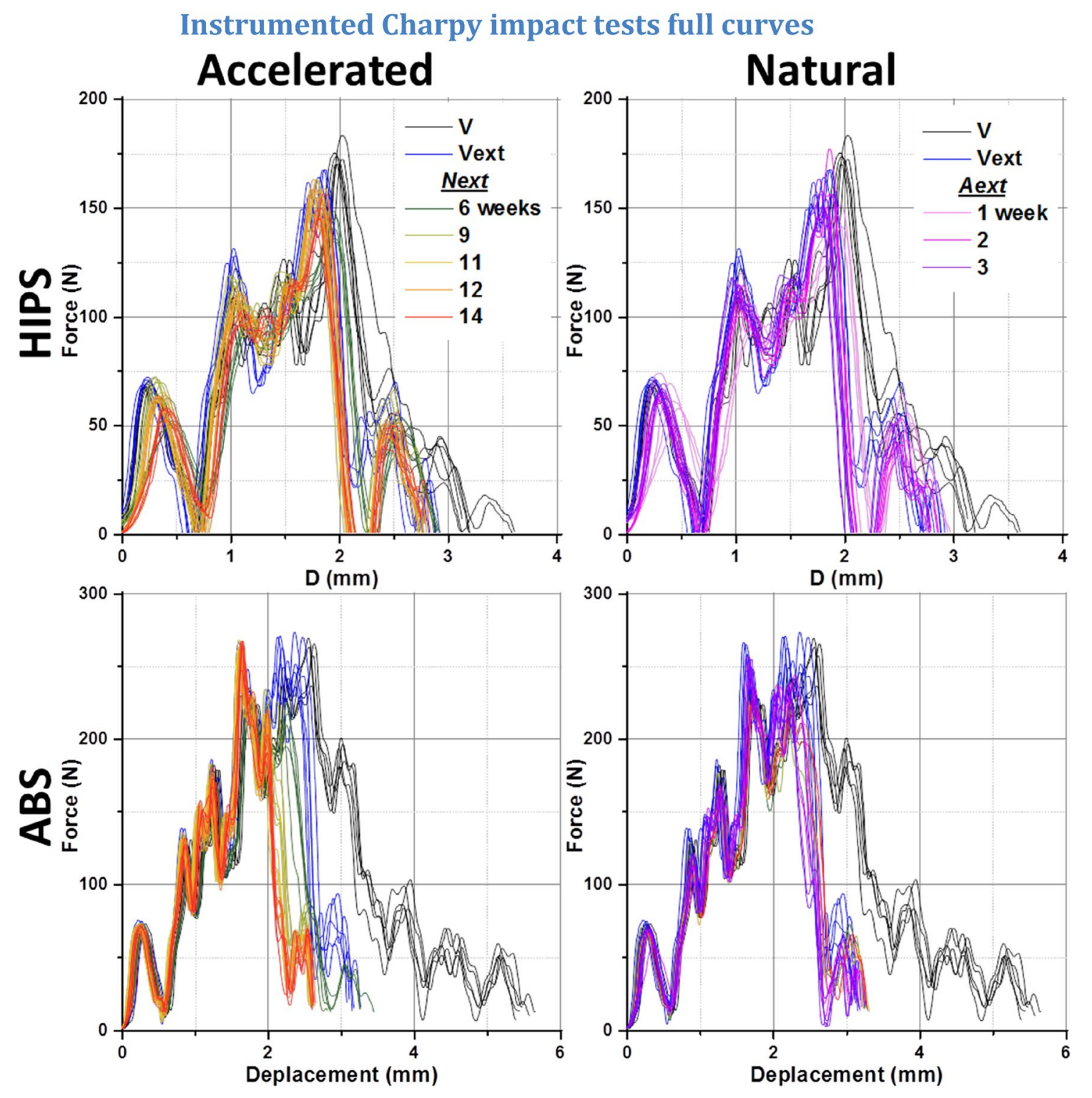

Fig. 23 Notched Charpy impact tests curves-ISO 179 1eA—HIPS \& ABS—accelerated and natural ageing—5 specimens/batch 

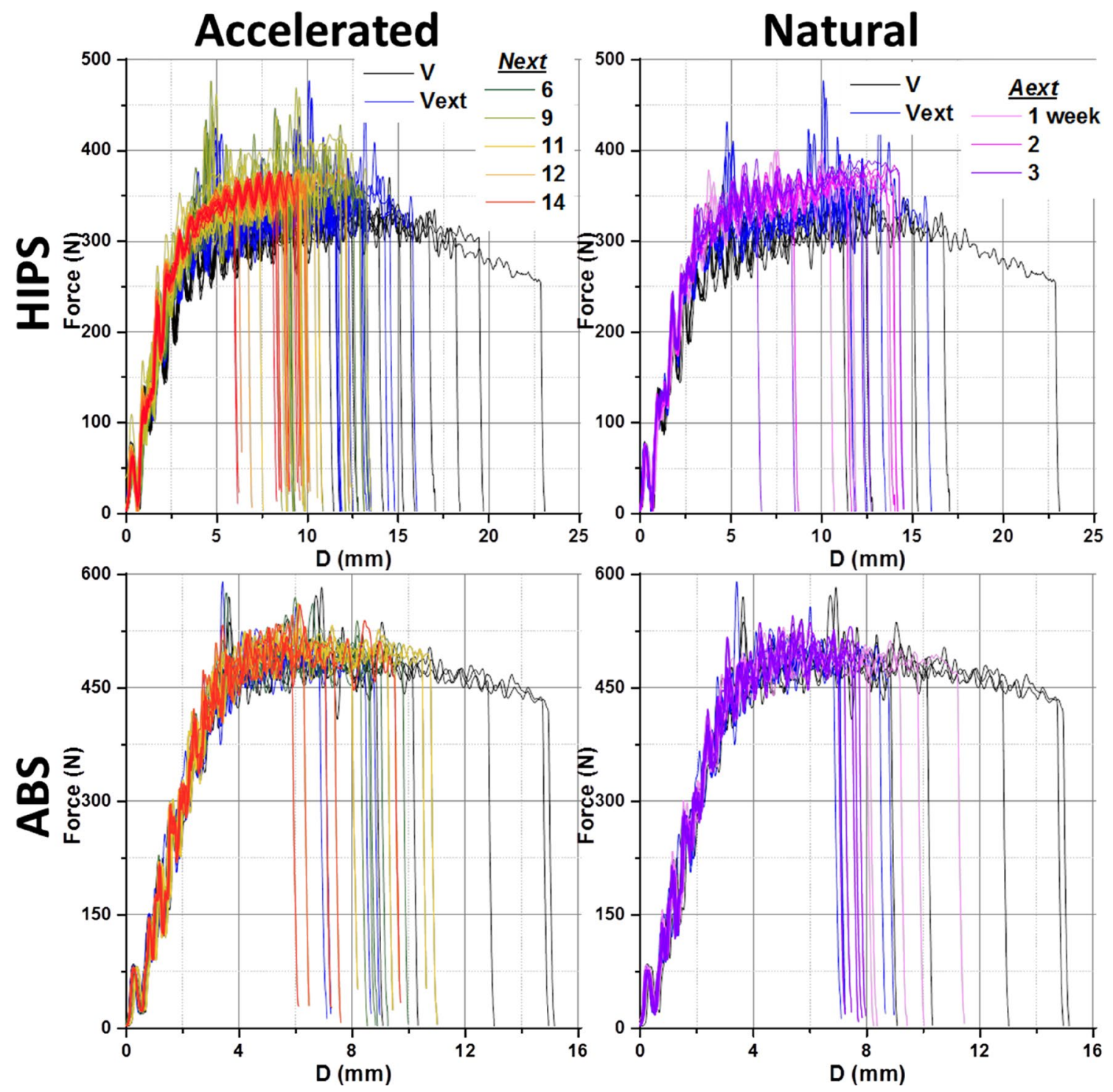

Fig. 24 Unnotched Charpy impact tests curves-ISO 179 1eA—accelerated and natural ageing - 10 specimens/batch for HIPS, 5 for ABS

\section{References}

1. Robinson BH (2009) E-waste: an assessment of global production and environmental impacts. Sci Total Environ 408:183-191. https ://doi.org/10.1016/j.scitotenv.2009.09.044

2. (2020) Earth Overshoot Day. In: Glob. Footpr. Netw. https://www. overshootday.org. Accessed 5 Mar 2020

3. Awasthi AK, Li J (2017) Management of electrical and electronic waste: A comparative evaluation of China and India. Renew Sustain Energy Rev 76:434-447. https://doi.org/10.1016/j. rser.2017.02.067

4. Salhofer S, Steuer B, Ramusch R, Beigl P (2016) WEEE management in Europe and China- a comparison. Waste Manag 57:27-35. https://doi.org/10.1016/j.wasman.2015.11.014

5. Kalmykova Y, Patrício J, Rosado L, Berg PEO (2015) Out with the old, out with the new-the effect of transitions in TVs and monitors technology on consumption and WEEE generation in Sweden
1996-2014. Waste Manag 46:511-522. https://doi.org/10.1016/j. wasman.2015.08.034

6. Bovea MD, Ibáñez-Forés V, Pérez-Belis V, Quemades-Beltrán $P$ (2016) Potential reuse of small household waste electrical and electronic equipment: methodology and case study. Waste Manag 53:204-217. https://doi.org/10.1016/j.wasman.2016.03.038

7. Lu B, Li B, Wang L et al (2014) Reusability based on Life Cycle Sustainability Assessment: case study on WEEE. Procedia CIRP 15:473-478. https://doi.org/10.1016/j.procir.2014.06.046

8. Zlamparet GI, Ijomah W, Miao Y et al (2017) Remanufacturing strategies: a solution for WEEE problem. J Clean Prod 149:126136. https://doi.org/10.1016/j.jclepro.2017.02.004

9. Quariguasi-Frota-Neto J, Bloemhof J (2012) An analysis of the eco-efficiency of remanufactured personal computers and mobile phones. Prod Oper Manag 21:101-114. https://doi.org/10.111 1/j.1937-5956.2011.01234.x

10. Javadi Y, Hosseini MS, Aghjeh MKR (2014) The effect of carbon black and HALS hybrid systems on the UV stability of 
high-density polyethylene (HDPE). Iran Polym J 23:793-799. https://doi.org/10.1007/s13726-014-0275-2

11. Liu M, Horrocks A (2002) Effect of Carbon Black on UV stability of LLDPE films under artificial weathering conditions. Polym Degrad Stab 75:485-499. https://doi.org/10.1016/S0141 $-3910(01) 00252-X$

12. Jouan X, Gardette JL (1992) Photo-oxidation of ABS: Part 2-origin of the photodiscoloration on irradiation at long wavelengths. Polym Degrad Stab 36:91-96. https://doi.org/10.1016/01413910(92)90054-9

13. Serranti S, Luciani V, Bonifazi G et al (2015) An innovative recycling process to obtain pure polyethylene and polypropylene from household waste. Waste Manag 35:12-20. https://doi. org/10.1016/j.wasman.2014.10.017

14. Beigbeder J, Perrin D, Mascaro J-F, Lopez-Cuesta J-M (2013) Study of the physico-chemical properties of recycled polymers from waste electrical and electronic equipment (WEEE) sorted by high resolution near infrared devices. Resour Conserv Recycl 78:105-114. https://doi.org/10.1016/j.resconrec.2013.07.006

15. Perrin D, Mantaux O, Ienny P et al (2016) Influence of impurities on the performances of HIPS recycled from Waste Electric and Electronic Equipment (WEEE). Waste Manag 56:438-445. https ://doi.org/10.1016/j.wasman.2016.07.014

16. Vilaplana F, Karlsson S (2008) Quality concepts for the improved use of recycled polymeric materials: a review. Macromol Mater Eng 293:274-297. https://doi.org/10.1002/mame.200700393

17. Brunner S, Fomin P, Kargel C (2015) Automated sorting of polymer flakes: fluorescence labeling and development of a measurement system prototype. Waste Manag 38:49-60. https://doi. org/10.1016/j.wasman.2014.12.006

18. Wang C, Wang H, Fu J, Liu Y (2015) Flotation separation of waste plastics for recycling - a review. Waste Manag 41:28-38. https:// doi.org/10.1016/j.wasman.2015.03.027

19. Langhals H, Zgela D, Schlücker T (2014) High performance recycling of polymers by means of their fluorescence lifetimes. Green Sustain Chem 04:144-150. https://doi.org/10.4236/ gsc. 2014.43019

20. Roh S-B, Oh S-K, Park E-K, Choi WZ (2017) Identification of black plastics realized with the aid of Raman spectroscopy and fuzzy radial basis function neural networks classifier. J Mater Cycles Waste Manag 19:1093-1105. https://doi.org/10.1007/ s10163-017-0620-6

21. Huang J, Tian C, Ren J, Bian Z (2017) Study on impact acoustic-visual sensor-based sorting of ELV plastic materials. Sensors 17:1325. https://doi.org/10.3390/s17061325

22. Costa VC, Aquino FWB, Paranhos CM, Pereira-Filho ER (2017) Identification and classification of polymer e-waste using laserinduced breakdown spectroscopy (LIBS) and chemometric tools. Polym Test 59:390-395. https://doi.org/10.1016/j.polym ertesting.2017.02.017

23. Barbier S, Perrier S, Freyermuth P et al (2013) Plastic identification based on molecular and elemental information from laser induced breakdown spectra: a comparison of plasma conditions in view of efficient sorting. Spectrochim Acta Part B 88:167-173. https://doi.org/10.1016/j.sab.2013.06.007

24. Küter A, Reible S, Geibig T et al (2018) THz imaging for recycling of black plastics. Tech Mess 85:191-201. https://doi. org/10.1515/teme-2017-0062

25. Maris E, Botané P, Wavrer P, Froelich D (2015) Characterizing plastics originating from WEEE: a case study in France. Miner Eng 76:28-37. https://doi.org/10.1016/j.mineng.2014.12.034

26. Martinho G, Pires A, Saraiva L, Ribeiro R (2012) Composition of plastics from waste electrical and electronic equipment (WEEE) by direct sampling. Waste Manag 32:1213-1217. https ://doi.org/10.1016/j.wasman.2012.02.010
27. Peeters JR, Vanegas P, Kellens K et al (2015) Forecasting waste compositions: a case study on plastic waste of electronic display housings. Waste Manag 46:28-39. https://doi.org/10.1016/j. wasman.2015.09.019

28. Stenvall E, Tostar S, Boldizar A et al (2013) An analysis of the composition and metal contamination of plastics from waste electrical and electronic equipment (WEEE). Waste Manag 33:915-922. https://doi.org/10.1016/j.wasman.2012.12.022

29. Han Y, Lach R, Grellmann W (1999) The Charpy impact fracture behaviour in ABS materials. Die Angew Makromol Chem 270:13-21. https://doi.org/10.1002/(SICI)1522-9505(19990 901)270:1\%3c13:AID-APMC13\%3e3.0.CO;2-P

30. Hirayama D, Saron C (2018) Morphologic and mechanical properties of blends from recycled acrylonitrile-butadiene-styrene and high-impact polystyrene. Polymer (United Kingdom) 135:271278. https://doi.org/10.1016/j.polymer.2017.12.038

31. Mercier JP, Maréchal E (1996) Chimie des polymères: synthèses, réactions, dégradations, 1 st edn. Presses Polytechniques et Universitaires Romandes, Lausanne

32. Moore J (1973) Acrylonitrile-butadiene-styrene (ABS)—a review. Composites 4:118-130. https://doi.org/10.1016/00104361(73)90585-5

33. Utracki LA (1998) Commercial polymer blends. Springer, Boston

34. Maestrini C, Pisoni K, Kausch HH (1996) On the elastic properties of rubber toughened Styrenics. J Mater Sci 31:3249-3257. https://doi.org/10.1007/BF00354676

35. Wypych G (2016) ABS poly(acrylonitrile-co-butadiene-co-styrene). Handbook of Polymers, pp 5-11

36. Alfarraj A, Bruce Nauman E (2004) Super HIPS: improved high impact polystyrene with two sources of rubber particles. Polymer (Guildf) 45:8435-8442. https://doi.org/10.1016/j.polym er.2004.10.005

37. Shimada J, Kabuki K (1968) The mechanism of oxidative degradation of ABS resin. Part II. The mechanism of photooxidative degradation. J Appl Polym Sci 12:671-682. https://doi. org/10.1002/app.1968.070120406

38. Vilaplana F, Karlsson S, Ribes-Greus A et al (2011) NMR relaxation reveals modifications in rubber phase dynamics during long-term degradation of high-impact polystyrene (HIPS). Polymer (Guildf) 52:1410-1416. https://doi.org/10.1016/j.polym er.2011.02.005

39. Tolue S, Moghbeli MR, Ghafelebashi SM (2009) Preparation of ASA (acrylonitrile-styrene-acrylate) structural latexes via seeded emulsion polymerization. Eur Polym J 45:714-720. https://doi. org/10.1016/j.eurpolymj.2008.12.014

40. Davis A, Gordon D (1974) Rapid assessment of weathering stability from exposure of polymer films. II. The effectiveness of different regions of the solar spectrum in degrading an ABS terpolymer. J Appl Polym Sci 18:1173-1179. https://doi.org/10.1002/ app.1974.070180415

41. Jouan X, Gardette J-L (1991) Photooxidation of ABS at longwavelengths. J Polym Sci Part A 29:685-696. https://doi. org/10.1002/pola.1991.080290510

42. Gardette J-L, Mailhot B, Lemaire J (1995) Photooxidation mechanisms of styrenic polymers. Polym Degrad Stab 48:457-470. https ://doi.org/10.1016/0141-3910(95)00113-Z

43. Saviello D, Pouyet E, Toniolo L et al (2014) Synchrotron-based FTIR microspectroscopy for the mapping of photo-oxidation and additives in acrylonitrile-butadiene-styrene model samples and historical objects. Anal Chim Acta 843:59-72. https://doi. org/10.1016/j.aca.2014.07.021

44. Mailhot B, Gardette J-L (1994) Mechanism of poly(styrene-coacrylonitrile) photooxidation. Polym Degrad Stab 44:237-247. https://doi.org/10.1016/0141-3910(94)90168-6

45. Tiganis B, Burn L, Davis P, Hill A (2002) Thermal degradation of acrylonitrile-butadiene-styrene (ABS) blends. Polym Degrad 
Stab 76:425-434. https://doi.org/10.1016/S0141-3910(02)00045 $-9$

46. Wang B, Zhao K, Zhang Y et al (2018) Influence of aging conditions on the mechanical properties and flame retardancy of HIPS composites. J Appl Polym Sci 135:46339. https://doi.org/10.1002/ app.46339

47. Vilaplana F, Ribes-Greus A, Karlsson S (2006) Degradation of recycled high-impact polystyrene. Simulation by reprocessing and thermo-oxidation. Polym Degrad Stab 91:2163-2170. https://doi. org/10.1016/j.polymdegradstab.2006.01.007

48. Pérez JM, Vilas JL, Laza JM et al (2010) Effect of reprocessing and accelerated weathering on ABS properties. J Polym Environ 18:71-78. https://doi.org/10.1007/s10924-009-0154-7

49. La Mantia F, Gardette J (2002) Improvement of the mechanical properties of photo-oxidized films after recycling. Polym Degrad Stab 75:1-7. https://doi.org/10.1016/S0141-3910(01)00199-9

50. Soccalingame L, Perrin D, Bénézet J-C et al (2015) Reprocessing of artificial UV-weathered wood flour reinforced polypropylene composites. Polym Degrad Stab 120:313-327. https://doi. org/10.1016/j.polymdegradstab.2015.07.013

51. Soccalingame L, Perrin D, Bénézet J-C, Bergeret A (2016) Reprocessing of UV-weathered wood flour reinforced polypropylene composites: study of a natural outdoor exposure. Polym Degrad Stab 133:389-398. https://doi.org/10.1016/j.polymdegradstab .2016.09.011

52. Pfaendner R, Herbst H, Hoffmann K, Sitek F (1995) Recycling and restabilization of polymers for high quality applications: an overview. Die Angew Makromol Chem 232:193-227. https://doi. org/10.1002/apmc.1995.052320113

53. Pfaendner R, Herbst H, Hoffmann K (1998) Innovative concept for the upgrading of recyclates by restabilization and repair molecules. Macromol Symp 135:97-111. https://doi.org/10.1002/ masy. 19981350112

54. Kiliaris P, Papaspyrides CD, Pfaendner R (2007) Reactiveextrusion route for the closed-loop recycling of poly(ethylene terephthalate). J Appl Polym Sci 104:1671-1678. https://doi. org/10.1002/app.25795

55. Kartalis C, Papaspyrides C, Pfaendner R (2000) Recycling of post-used PE packaging film using the restabilization technique. Polym Degrad Stab 70:189-197. https://doi.org/10.1016/S0141 -3910(00)00106-3

56. Tsenoglou CJ, Kartalis CN, Papaspyrides CD, Pfaendner R (2002) Restabilization of recycled, $\mathrm{CaCO}_{3}$-filled polypropylene: assessment of reprocessing induced modifications and processing stabilizer effectiveness. Adv Polym Technol 21:260-267. https://doi. org/10.1002/adv.10026

57. Kartalis CN, Papaspyrides CD, Pfaendner R et al (2000) Mechanical recycling of post-used HDPE crates using the restabilization technique. II: Influence of artificial weathering. J Appl Polym Sci 77:1118-1127. https://doi.org/10.1002/1097-4628(20000 801)77:5\%3c1118:AID-APP20\%3e3.3.CO;2-A

58. Craig IH, White JR (2006) Mechanical properties of photodegraded recycled photo-degraded polyolefins. J Mater Sci 41:993-1006. https://doi.org/10.1007/s10853-006-6596-6

59. Luzuriaga S, Kovářová J, Fortelný I (2006) Degradation of preaged polymers exposed to simulated recycling: properties and thermal stability. Polym Degrad Stab 91:1226-1232. https://doi. org/10.1016/j.polymdegradstab.2005.09.004

60. Boldizar A, Möller K (2003) Degradation of ABS during repeated processing and accelerated ageing. Polym Degrad Stab 81:359366. https://doi.org/10.1016/S0141-3910(03)00107-1

61. Stenvall E (2013) Electronic waste plastics characterisation and recycling by melt-processing. Chalmers University of Technology, Göteborg

62. Hygro Button-The smallest temperature and humidity logger in the world! In: Proges Plus. https://www.proges.com/en/ plug-and-track/temperature-data-loggers/hygro-button-temperatur e-and-humidity-logger.html. Accessed 14 Feb 2019

63. QUV Accelerated Weathering Tester. In: Q-LAB. https://www.qlab.com/products/quv-weathering-tester/quv. Accessed $14 \mathrm{Feb}$ 2019

64. Pickett JE, Gibson DA, Gardner MM (2008) Effects of irradiation conditions on the weathering of engineering thermoplastics. Polym Degrad Stab 93:1597-1606. https://doi.org/10.1016/j. polymdegradstab.2008.02.009

65. Wyszecki G, Stiles WS (2000) Color science: concepts and methods, quantitative data and formulae, 2nd edn. Wiley, New York

66. Alassali A, Fiore S, Kuchta K (2018) Assessment of plastic waste materials degradation through near infrared spectroscopy. Waste Manag 82:71-81. https://doi.org/10.1016/j.wasman.2018.10.010

67. Santos RM, Botelho GL, Machado AV (2010) Artificial and natural weathering of ABS. J Appl Polym Sci 21:2005-2014. https:// doi.org/10.1002/app.31663

68. Santos RM, Botelho GL, Cramez C, Machado AV (2013) Outdoor and accelerated weathering of acrylonitrile-butadiene-styrene: a correlation study. Polym Degrad Stab 98:2111-2115. https://doi. org/10.1016/j.polymdegradstab.2013.07.016

69. Scaffaro R, Maio A (2019) Influence of oxidation level of graphene oxide on the mechanical performance and photo-oxidation resistance of a polyamide 6. Polymers (Basel) 11:857. https://doi. org/10.3390/polym 11050857

70. Xingzhou H, Zubo L (1995) Wavelength sensitivity of photooxidation of styrene-butadiene-styrene copolymer. Polym Degrad Stab 48:99-102. https://doi.org/10.1016/0141-3910(95)00011-A

71. Searle ND, Maecker NL, Crewdson LFE (1989) Wavelength sensitivity of acrylonitrile-butadiene-styrene. J Polym Sci Part A 27:1341-1357. https://doi.org/10.1002/pola.1989.080270418

72. Arráez FJ, Arnal ML, Müller AJ (2018) Thermal degradation of high-impact polystyrene with pro-oxidant additives. Polym Bull. https://doi.org/10.1007/s00289-018-2453-4

73. Mylläri V, Ruoko T-PP, Syrjälä S (2015) A comparison of rheology and FTIR in the study of polypropylene and polystyrene photodegradation. J Appl Polym Sci. https://doi.org/10.1002/ app.42246

74. Birchmeier M, Priddy DB, Smith PB et al (2005) Thermal styreneco-acrylonitrile discoloration problem: the role of sequence distribution and oligomers. Macromolecules 26:6068-6075. https:// doi.org/10.1021/ma00074a030

75. Audouin L, Langlois V, Verdu J, de Bruijn JCM (1994) Role of oxygen diffusion in polymer ageing: kinetic and mechanical aspects. J Mater Sci 29:569-583. https://doi.org/10.1007/BF004 45968

76. Kuvshinnikova O, Boven G, Pickett JE (2019) Weathering of aromatic engineering thermoplastics: comparison of outdoor and xenon arc exposures. Polym Degrad Stab 160:177-194. https:// doi.org/10.1016/j.polymdegradstab.2018.12.011

77. Hirschler R (2016) Whiteness, Yellowness, and Browning in Food Colorimetry. In: Caivano JL, del Pilar BM (eds) Color in food: technological and psychophysical aspects, 1st edn. CRC Press, Boca Raton, pp 93-103

78. Achtioui T, Lacoste C, Le Baillif M, Erre D (2018) Prediction of the yellowing of styrene-stat-acrylonitrile and acrylonitrilebutadiene-styrene during processing in an internal mixer. J Polym Eng 38:983-993. https://doi.org/10.1515/polyeng-2017-0305

79. Bai X, Isaac DH, Smith K (2007) Reprocessing acrylonitrile-butadiene-styrene plastics: Structure-property relationships. Polym Eng Sci 47:120-130. https://doi.org/10.1002/pen.20681

80. Karahaliou E-K, Tarantili PA (2009) Stability of ABS compounds subjected to repeated cycles of extrusion processing. Polym Eng Sci 49:2269-2275. https://doi.org/10.1002/pen.21480

81. Şahin T, Sınmazçelik T, Şahin Ş (2007) The effect of natural weathering on the mechanical, morphological and 
thermal properties of high impact polystyrene (HIPS). Mater Des 28:2303-2309. https://doi.org/10.1016/j.matdes.2006.07.013

82. Bottino FA, Cinquegrani AR, Di Pasquale G et al (2004) Chemical modifications, mechanical properties and surface photo-oxidation of films of polystyrene (PS). Polym Test 23:405-411. https://doi. org/10.1016/j.polymertesting.2003.10.001

83. Brennan LB, Isaac DH, Arnold JC (2002) Recycling of acrylonitrile-butadiene-styrene and high-impact polystyrene from waste computer equipment. J Appl Polym Sci 86:572-578. https://doi. org/10.1002/app.10833 